\title{
Coupling and Decoupling of Reproduction and Larval Recruitment
}

\author{
Steven G. Morgan ${ }^{1}$ \\ Received: 23 April 2020 / Revised: 11 May 2021 / Accepted: 14 May 2021 / Published online: 24 June 2021 \\ (C) The Author(s) 2021
}

\begin{abstract}
Stock-recruitment relationships for managing commercial fisheries are difficult to measure and notoriously poor, so marine ecologists have relied on larval recruitment as a proxy for how planktonic processes regulate populations and communities. However, my literature review revealed that coupling between reproductive output and recruitment in benthic populations was common, occurring in $62 \%$ of 112 studies and $64 \%$ of 81 species. Coupling was considerably stronger for studies on brooders (72\%) than broadcast-spawners (46\%) and taxa with short (74\%) than long (56\%) planktonic larval durations (PLDs); hence, it was highest for brooders with short PLDs (94\%). Coupling was similar in studies on benthic animals (63\%) and seagrasses and kelp $(56 \%)$. Coupling was detected more often by quantifying both reproductive output and settlement (79\%) than adult density and recruitment (60\%). It also was detected in $83 \%$ of just $21 \%$ of studies that estimated dispersal. Coupling was even detected by $55 \%$ of the $46 \%$ of studies conducted at just one site and $58 \%$ of the $65 \%$ of studies lasting no longer than 3 years. Decoupling was detected 33 times in invertebrates and fishes, occurring more often in the plankton (48.5\%) and during reproduction (45.5\%) than after settlement $(6 \%)$, and nine times in seagrasses and kelp, occurring more often during reproduction (44.4\%) than postsettlement $(33.3 \%)$ or in the plankton $(22.2 \%)$. Widespread coupling between reproductive output and settlement for sedentary, benthic species suggests that the poor stock-recruitment relationships typical of vagile, wide-ranging, pelagic species may be due more to the difficulty of detecting them than decoupling.
\end{abstract}

Keywords Coupling $\cdot$ Stock-recruitment $\cdot$ Larvae $\cdot$ Brooders $\cdot$ Broadcasters $\cdot$ Seagrasses

\section{Introduction}

Understanding population dynamics in the sea is especially challenging because populations are regulated during both the adult and larval phases of typical marine life cycles. The larval phase is exceedingly difficult to study because the vast majority of species produce thousands of microscopic larvae that develop for weeks in a dynamic ocean. Consequently, it is hard to know whether the number of larvae recruiting to a population is related to the number of larvae produced (coupling) or whether planktonic processes disrupt the relationship (decoupling). Larvae are thought to suffer high mortality while potentially being carried by currents far from natal populations decoupling this relationship, because recruitment to populations is typically highly episodic bearing little

Communicated by Kenneth L. Heck

Steven G. Morgan

sgmorgan@ucdavis.edu

1 Bodega Marine Laboratory, Coastal Marine Sciences Institute, and Department of Environmental Science and Policy, University of California, Davis, Bodega Bay, CA 93514, USA relationship to the number of larvae produced (Hjort 1914; Thorson 1950). However, the fate of larvae is largely unknown because tiny larvae cannot be tracked for weeks in the ocean. Hence, most of our knowledge is drawn from inferential empirical studies and theoretical models. It is essential to determine the frequency and extent of coupling between reproductive output and settlement (defined here as $<1$ day after larvae settle as opposed to recruitment, which is defined as $>1$ day after settlement) and the causes of decoupling for fisheries biologists, ecologists and evolutionary biologists to know how the supply of larvae to adult populations is regulated.

Poor relationships between reproduction and recruitment observed by ecologists and fisheries biologists led to the belief that the adult and larval phases of typical marine life cycles are often decoupled (Morgan 1995; Marshall and Morgan 2011; Szuwalski et al. 2015). After all, several critical links in the larval phase of the life cycle all must go right for larvae to recruit to adult populations, including fertilization of gametes by broadcast-spawners in the water column, larval survival (avoiding predation, food limitation, physiological stress and advection far from adult habitats) and settlement in a suitable habitat for benthic species (Fig. 1). At least, relationships 


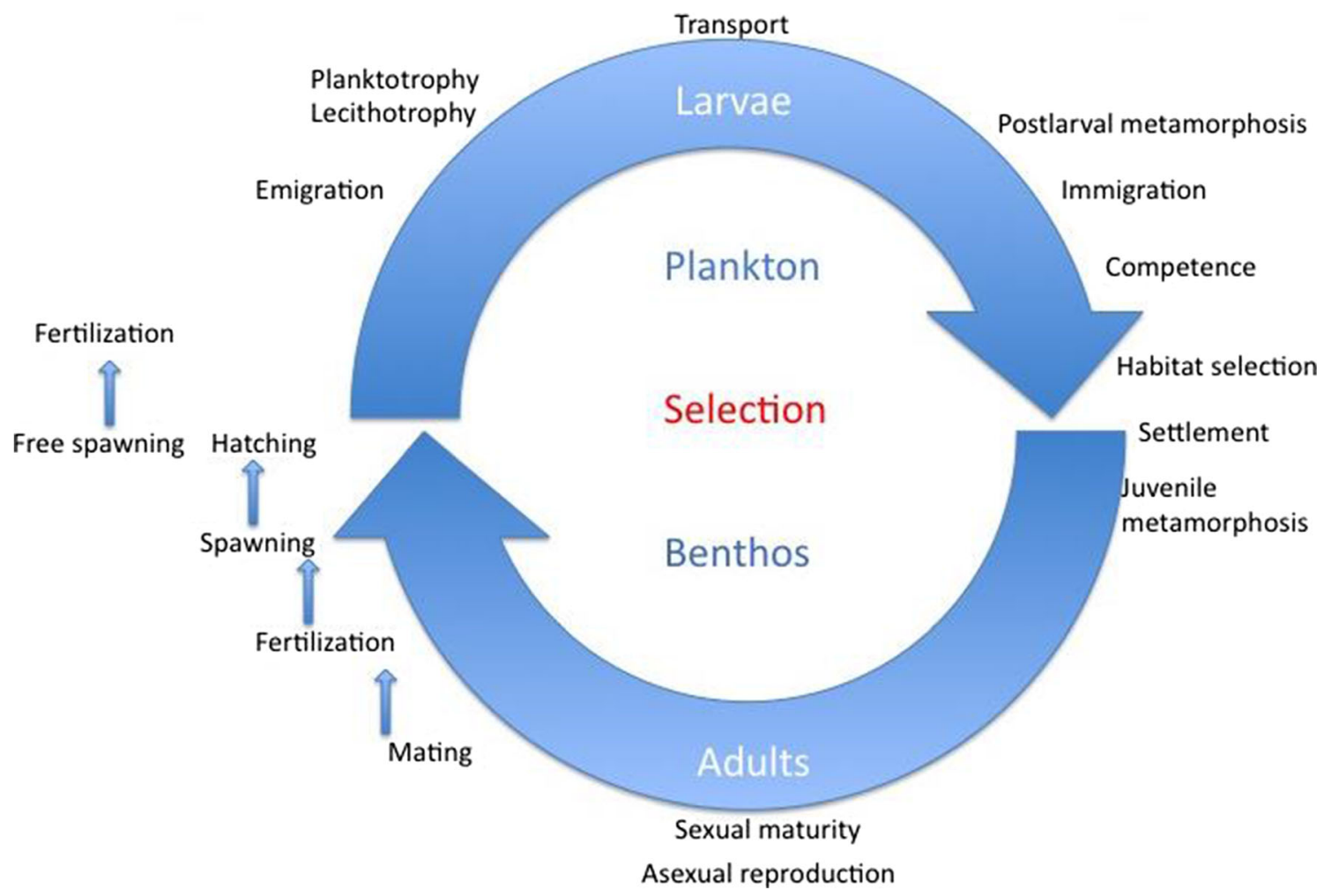

Fig. 1 Critical junctures in the life cycles of benthic marine animals with internal or external fertilization and planktonic development. Key environmental factors that can decouple reproductive output and settlement success also are depicted

between reproduction and recruitment are difficult to detect. Consequently, ecologists tended to focus primarily on the adult phase while using larval recruitment as a proxy for studying the planktonic phase (Morgan 2001; Underwood and Keough 2001). Fisheries biologists do not have this luxury because they are charged with forecasting fisheries yields and managing stocks by relating the number of adults to the recruitment of juveniles to the adult population following planktonic larval development (PLD). Although approaches to determining stock-recruitment relationships improved over decades, relationships were still weak or not detected (Myers and Mertz 1998; Sakuramoto 2005; Cury et al. 2014; Szuwalski et al. 2015; Pepin 2016). Environmental causes of poor relationships were increasingly investigated by expanding the initial emphasis on foraging success of larvae to include larval dispersal, predation and physiological stress (Koster et al. 2003; Hare 2014; Haltuch et al. 2019). However, recruitment for commercial species refers to juveniles entering the fishery of adult populations rather than larval recruitment to suitable settlement sites so that density dependence and other factors affecting juveniles damp the effect of environmental factors on growth and survival in the plankton (Myers and Mertz 1998; Sakuramoto 2005; Ohlberger et al. 2014). Factors affecting adults also are considered in stock-recruitment relationships, including migration, spatial population structure and connectivity, trophic interactions and fishing mortality (Hare 2014; Travis et al. 2014; Cadrin et al. 2019).
Untangling the impact of spawning stock and environmental factors on recruitment success may be best determined by following a year class through the successive stages of the life cycle, including viable egg production, survival of eggs, larvae and juveniles, and growth and maturation of adults relative to prevailing environmental conditions (Paulik 1973), but this approach has seldom been attempted for commercial species (Koster et al. 2003). Determining whether the adult and larval phases are coupled is simpler for benthic ecologists, who can just quantify reproductive output and settlement while identifying the causes of decoupling in the plankton. Determining whether decoupling occurs during the release of gametes or larvae into the water column requires quantifying both reproductive output and first-stage larvae. Determining whether decoupling occurs while larvae are developing and dispersing in the plankton or settling in suitable habitat for juveniles requires quantifying both last-stage larvae or postlarvae and settlers. Mortality after settlement also can be tracked to quantify early postsettlement mortality. It is essential to concurrently monitor environmental variables to identify likely causes of decoupling. The struggle to understand interannual variation in relationships between the reproductive output and recruitment continues, because it is fundamental for determining population persistence and resilience to conserve and manage marine populations.

The primary objective of this review was to assess (1) the frequency of coupling between reproductive output and 
recruitment, (2) how often each stage of early life histories was quantified and (3) the most common causes of decoupling, which are suspected of being advection from natal populations, predation and food limitation (Hjort 1914; Thorson 1950; Cushing 1990; Rumrill 1990; Morgan 1995; Hare 2014). I focused on benthic species, including diverse invertebrates, coral reef fishes, seagrasses and kelp, because population size, reproductive output and recruitment are simpler to reliably estimate for sessile or sedentary adults that inhabit discrete habitats, such as coral and oyster reefs, kelp and seagrass beds, rocky, sandy and muddy shores, and estuaries and bays, than for vagile, wide-ranging pelagic species. Coupling is easier to detect because propagules must recruit to these discrete habitats to survive. Furthermore, stockrecruitment relationships of vagile, wide-ranging, commercial fishes have already been reviewed extensively (e.g., Myers and Mertz 1998; Cury et al. 2014; Hare 2014; Szuwalski et al. 2015; Pepin 2016). Thus, my review concentrates on the body of literature that is most likely to detect coupling, and it is intended to be illustrative rather than exhaustive.

My second objective was to evaluate the consequences of different life histories on coupling of reproductive output and recruitment. Marine species vary widely in reproductive mode and PLD, which both affect dispersal and mortality of larvae in the plankton (Morgan 1995; Sponaugle et al. 2002; Strathmann et al. 2002; Burgess et al. 2016). The longer propagules spend in the plankton, the more likely they will be advected from natal populations or die. A large majority of marine animals broadcast gametes into the water where fertilized eggs disperse passively in currents until they develop into weakly swimming larvae (Giese and Khanatani 1987; Thresher 1990; Fig. 2). Far fewer species provision more yolk to offspring and brood embryos internally or externally, thereby investing more time and energy in caring for them (Giese and Khanatani 1987; Thresher 1990). Larvae hatch at a more advanced stage of development and are larger, stronger swimmers that mediate dispersal (Fig. 2). In general, coupling may be easier to detect for these species because more larvae will recruit to the populations being studied rather than going unaccounted for by dispersing to locations beyond the study area. I included seagrasses and kelp that produce passively dispersing seeds or spores in contrast with sessile and sedentary species of animals that disperse by swimming larvae (Fig. 2). Despite the lack of behavior, seeds have morphological traits that may either decrease or increase dispersal, depending on the species (Burgess et al. 2016). The life histories of sessile brooders with short larval durations may be most similar to seagrasses and kelp (Fig. 2), because both fertilize eggs internally and settle soon after propagules are released.

My third objective was to evaluate how well studies are designed to detect coupling. Coupling certainly occurs at very large spatial scales and long temporal scales. However, most studies are conducted at small spatial scales and short temporal scales begging the question how often coupling is detected in a dynamic ocean at these scales. Studies conducted over just 1 year may or may not detect coupling, but studies conducted over many years can determine the frequency of coupling. Similarly, studies that incorporate multiple locations over large scales are more likely to detect coupling than studies with a single site because they usually will capture dispersing

\section{Eelgrass}
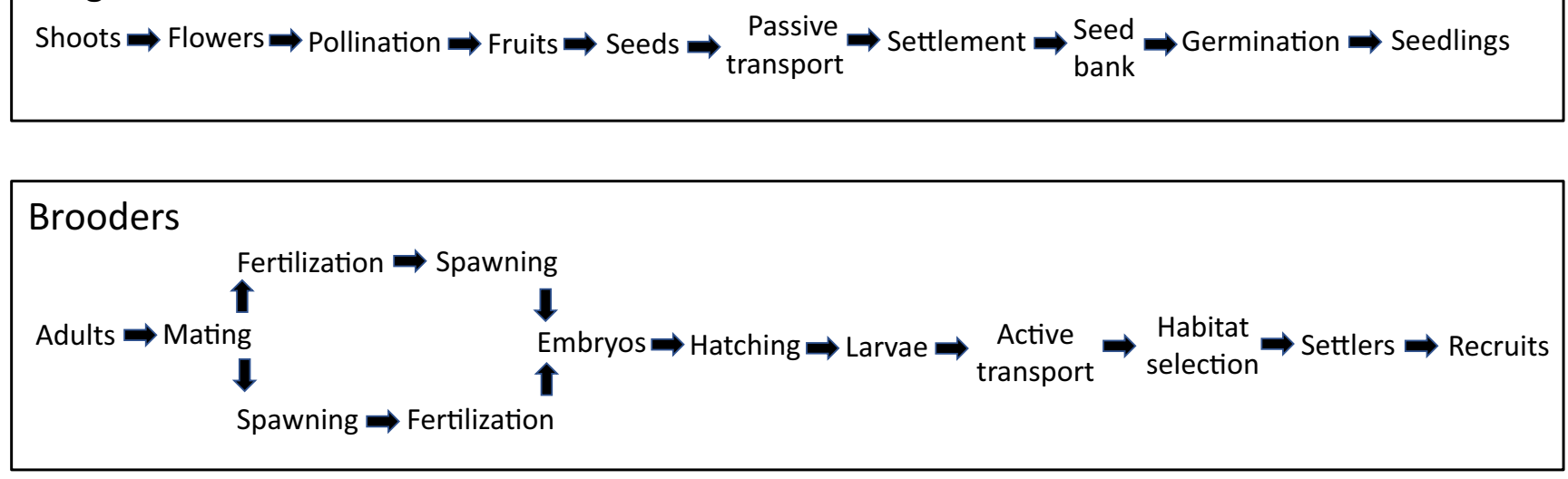

\section{Broadcasters \\ Adults $\Rightarrow$ Spawning $\Rightarrow$ Fertilization $\Rightarrow$ Embryos $\Rightarrow \underset{\text { transport }}{\text { Passive }} \Rightarrow$ Larvae $\Rightarrow \underset{\text { transport }}{\text { Active }} \rightarrow \begin{gathered}\text { Habitat } \\ \text { selection }\end{gathered} \Rightarrow$ Settlers $\Rightarrow$ Recruits}

Fig. 2 Stages during sexual reproduction of eelgrasses and brooding and broadcasting benthic animals. Brooders either fertilize gametes internally or externally 
larvae and include retention hotspots. Incorporating a hierarchical sampling design should best capture the extent of coupling between reproductive output and settlement. The comparative approach can strengthen conclusions about coupling. Concurrently studying species with different life history traits, such as reproductive mode and PLD, provides a direct comparison of the degree of coupling under the same environmental conditions. Similarly, comparing multiple species with similar reproductive modes and PLDs reinforces the degree of coupling under the same environmental conditions for that type of life history.

The degree of coupling is usually determined by calculating the relationship between reproductive output or adults and settlement or recruitment for a population, referred to as the stock-recruitment relationship in the fisheries literature (hereafter SRR). Regression analysis of reproductive output or adults versus settlement or recruitment provides a simple metric of the degree of coupling and statistical significance. However, both larval mortality and dispersal determine the degree of coupling so estimates of coupling will be improved by quantifying larvae leaving the population and arriving from neighboring populations. Hence, I also included estimates of the percentage of propagules that settled or recruited to the study area, the number of propagules settling or recruiting to two or more sites within the study area and the distance that propagules dispersed. I refer to the calculation of a SRR across more than one site as a spatial SRR. Studies that are conducted at multiple sites and incorporate dispersal yield data that often require more complex analysis than a spatial SRR, including complementary studies on larval dispersal, such as parentage analysis, natural elemental markers and models. In addition to these studies, I also included studies that did not analyze data because the relationship between reproductive output and settlement was clear without it. Although the focus was on the planktonic phase of the life cycle, I also examined early postsettlement mortality and density dependence, which also can be bottlenecks regulating populations.

Including studies that use these diverse approaches in my review provides a more comprehensive evaluation of how often coupling occurs. However, drawing on diverse approaches to evaluate coupling between reproductive output or adults and settlement or recruitment precluded a metanalysis that would provide a quantitative measure of the degree of coupling. The diverse types of data also precluded arbitrarily categorizing results as weak, strong or moderate coupling, as would need to be done for stock-recruitment relationships without a level of statistical significance or dispersal to or from the study area. Instead, I addressed the expectations posed in the three objectives by summarizing studies and highlighting whether or not (1) relationships between reproductive output or adults and settlement or recruitment were significant, (2) propagules were commonly retained and settled the study area and (3) whether the author(s) concluded that reproduction and recruitment were coupled or decoupled. This simplistic approach yields yes-or-no conclusions that are easily presented and a broader appreciation of how often coupling is detected.

For each study, I documented the (1) intervening life stages and processes quantified, (2) temporal and spatial scale of the study, (3) method of estimating dispersal and (4) likely cause of decoupling. For animals, the intervening life stages and processes quantified were adult densities, reproductive output, larval concentrations, settler densities, recruit densities and postsettlement mortality. For seagrasses, I reported whether populations were composed of annuals, perennials or a mixture of the two life history types. The life stages and processes quantified were shoot densities, densities of flowering shoots, percentage of fertilized flowers, seed production, density of seeds in the seed bank, percentage of germinated seeds in the seed bank and seedling recruitment. I reported the number of years (reproductive seasons) and sites and the approximate length of coastline surveyed. I also reported whether the scale of dispersal was estimated using a hierarchical sampling design, parentage analysis, natural elemental markers, visual tracking, modeling or drifters. I categorized whether the likely causes of decoupling occurred during reproduction, planktonic development or postsettlement to assess the weakest link in early life histories. I also highlighted whether the comparative approach was used to contrast species with different reproductive modes or PLDs or compare species with similar life history traits in a single study. I tabulated the results by species and organized tables by taxon. I tallied the number of species and considered genera or higher taxa to be different species given that the complement of species is unknown. I tallied the number and percentage of studies that investigated each intervening life stage, estimated dispersal, reported statistical SRRs, reported instances of decoupling and detected coupling. I also tallied the number of studies, years and study sites and then calculated the mean percentage of studies, mean number of years and study sites and mean distance spanning sites.

I determined the percentage of studies and species in which coupling was detected for each of the five common types of life histories: (1) seagrasses and kelp releasing passive seeds or spores with short planktonic durations, (2) brooders releasing swimming competent larvae with short PLDs, (3) broadcasters releasing passive eggs developing into swimming precompetent larvae with short PLDs, (4) brooders releasing swimming precompetent larvae with long PLDs and (5) broadcast-spawners releasing passive eggs developing into swimming larvae with long PLDs. I first covered species with short PLDs ( $\leq 1$ week), because coupling is more likely to occur and be detected for these species than those with long PLDs (> 1 week). Within this group, I began by considering brooders because their larvae are better able to regulate dispersal, thereby increasing coupling between reproductive 
output and settlement. I first presented examples of noncommercial species investigated by ecologists before presenting examples of commercial species studied by fisheries biologists for both brooders and broadcasters. Detecting coupling between reproduction and recruitment of noncommercial species may be easier because commercial species are typically more vagile and widespread, although commercial species often have longer timeseries of data.

I began the discussion by reporting the overall percentage of studies and species in which coupling was detected and the metrics used to make the determination. I then discussed the degree of coupling among life histories of animals and among animals, seagrasses and kelp. Next, I discussed the importance of the study design in detecting coupling, the stage that reproductive failure occurred and likely causes of decoupling. I concluded by highlighting take-home messages regarding the implications for the dynamics of populations and communities, evolution of life histories and future research.

\section{Evidence for Coupling and Decoupling of Reproduction and Larval Recruitment}

\section{Seagrasses and Kelp Releasing Passive Seeds or Spores with Short Planktonic Durations ( $\leq 1$ Week)}

Coupling occurred in 56\% of 16 studies and nine species of seagrasses and kelp, including eight species of seagrasses and one species of kelp, from 13 papers (Fig. 3A). For seagrasses, coupling occurred in $53 \%$ of 15 studies and $50 \%$ of the eight species from 12 papers (Table 1). Statistics were reported in only $20 \%$ of studies. A SRR with or without statistics was determined in one and 11 studies, respectively, and a spatial SRR with or without statistics was determined in two and one study (Table 1). The SRR was compared before, during and after a die-off of a population in three of these studies. Coupling in seagrasses was common even though most studies were brief, averaging 2.1 years, and at just one site with an average of 2.6 sites (Table 1). Five studies were conducted at more than one site, averaging 5.8 sites spanning $57.8 \mathrm{~km}$. Propagule dispersal was quantified in only one study (Reed et al. 2009). Twelve populations of seagrasses were perennial, two populations were annual and one population was mixed being composed of both perennial and annual seagrasses and kelp (Table 1). Coupling in annual and perennial populations was contrasted in four studies and coupling of two species of surfgrasses was compared in one study. Intervening stages between reproductive output and recruitment were quantified in most studies. Shoots, flowering shoots, seed production and seedling recruitment/mortality were quantified in $100 \%$ of the 15 studies, the seed bank and seed germination were quantified in 53\% and fertilized flowers were quantified in only $20 \%$ of these studies (Table 1; Fig. 4). Decoupling in time or space occurred in $60 \%$ of the studies on seagrasses, and in these studies, it likely resulted from stressful environmental conditions disrupting reproduction (33\%) and pollen limitation
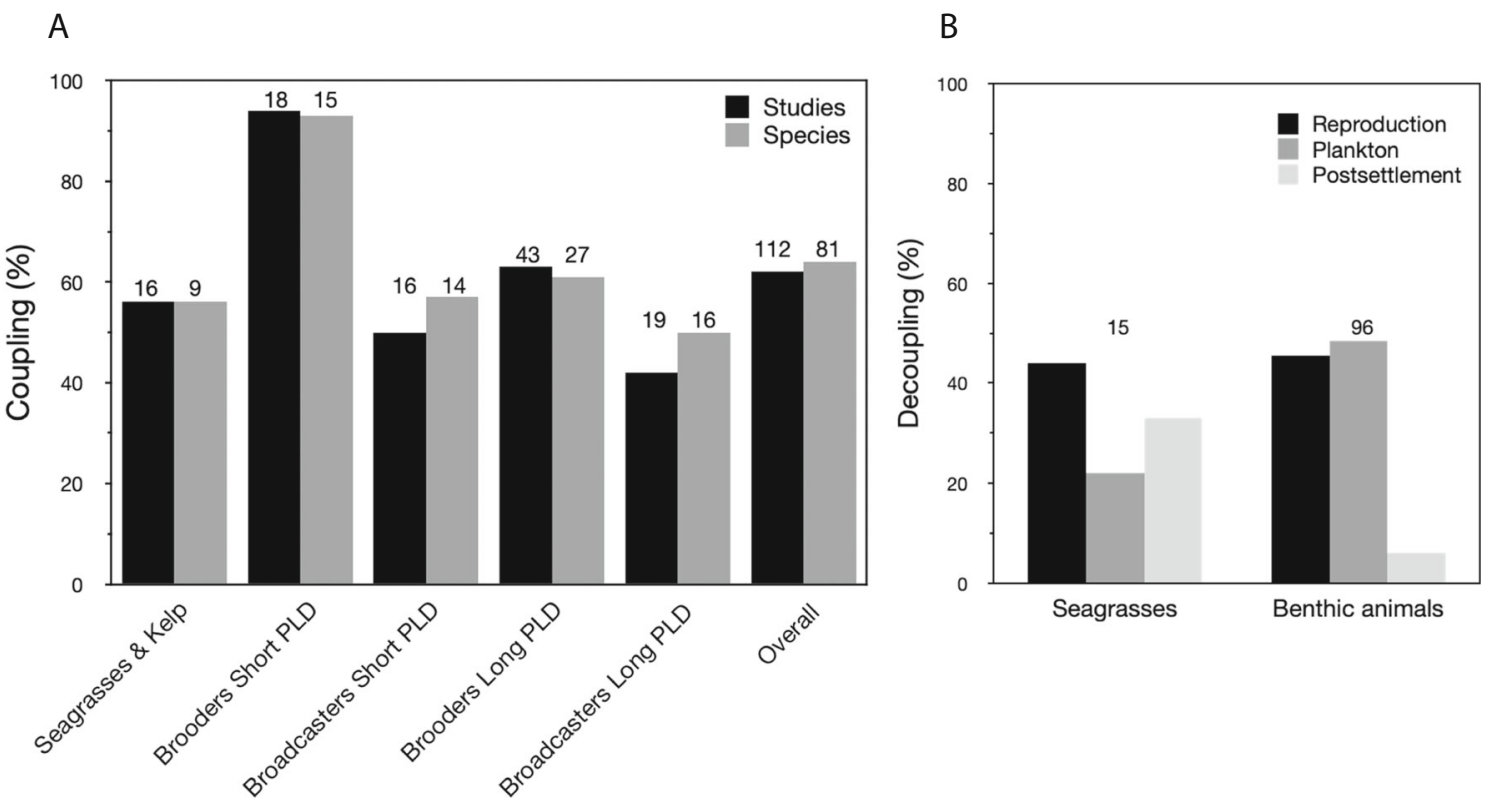

Fig. 3 A) Percent coupling of reproduction and recruitment of seagrasses and kelp, brooders with short ( $<1$ week) and long ( $>1$ week) planktonic larval durations (PLDs), broad̄asters with short and long PLDs and overall for the number of studies and species reviewed (numbers above

bars). B) Percentage of studies that detected decoupling during the reproductive, planktonic or postsettlement phases of the life cycles of seagrasses (15 studies) and benthic animals (33 studies) 


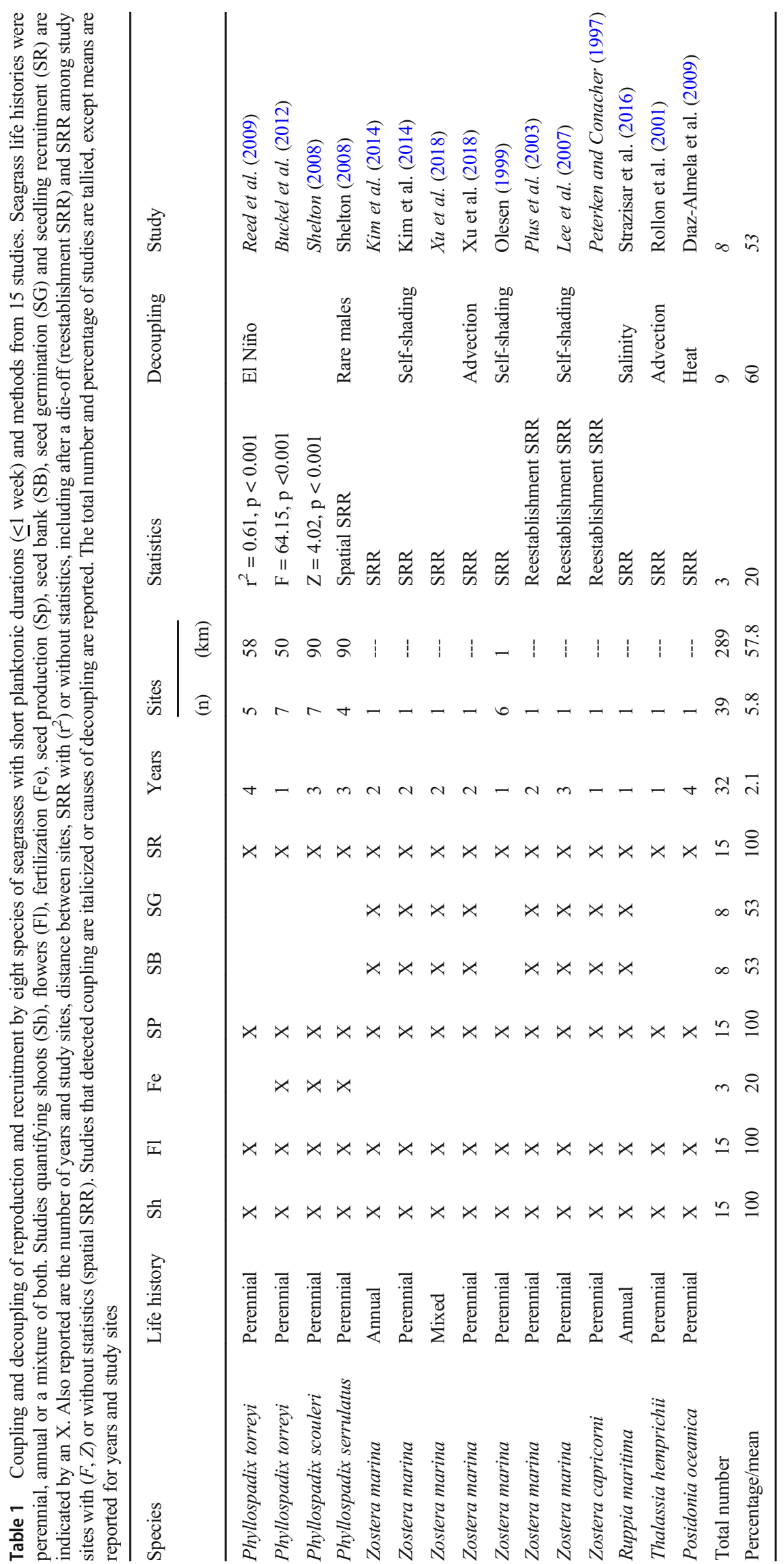


Fig. 4 Percentage of 15 reviewed studies on seagrasses that quantified flowering shoots, fertilized flowers, seed production, the seed bank, seed germination and seedling recruitment

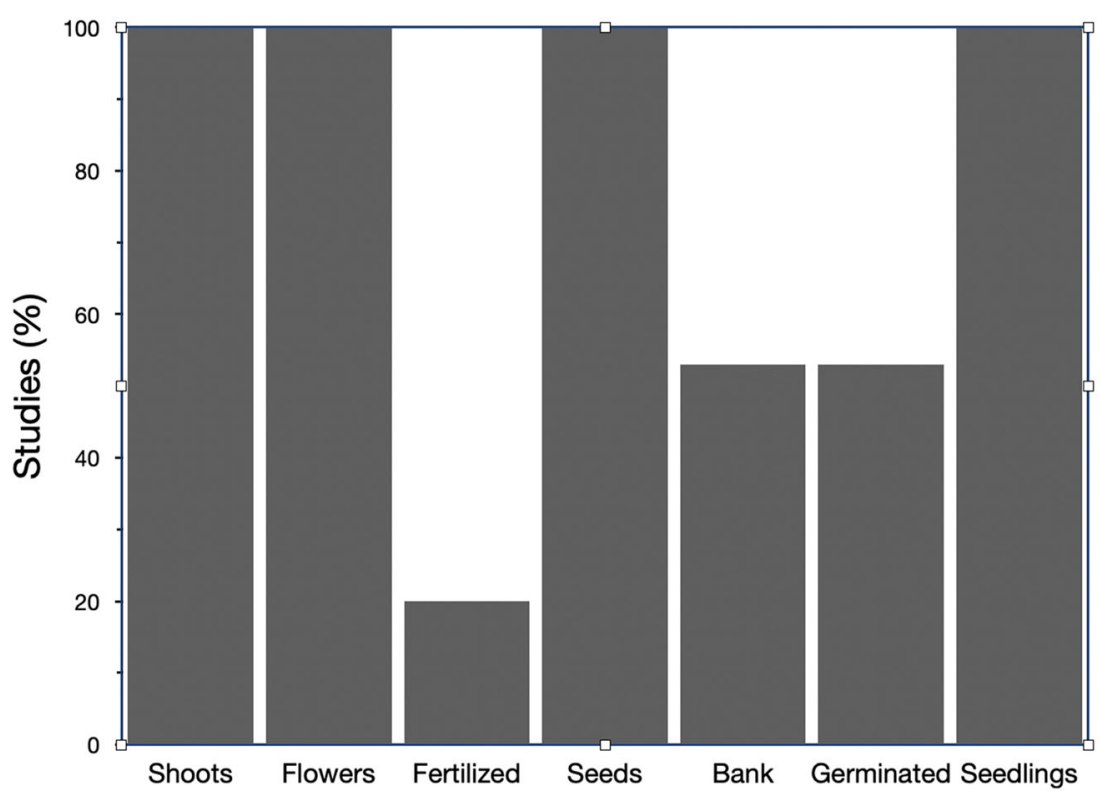

(11\%), advection of seeds or seedlings (22\%) and early postsettlement mortality from competition of seedlings with established shoots (33\%; Table 1). Thus, decoupling occurred more often during reproduction $(44 \%)$ than in the plankton $(22 \%)$ or postsettlement (33\%; Fig. $3 \mathrm{~B})$.

Coupling occurred in $75 \%$ of four studies and $67 \%$ of three species of surfgrasses from three papers (Table 1) and primarily was determined by fertilization success. Decoupling occurred twice, once by pollen limitation and once during El Niño. Coupling was determined by the local production and deposition of seeds and temporal and spatial variation in seedling density of Phyllospadix torreyi at five sites along $58 \mathrm{~km}$ of coast near Santa Barbara, CA, USA, during 3 of 4 years (Reed et al. 2009). The density of dehisced female spadices (spikes of minute flowers) explained $41 \%$ of the variation in the number of seeds caught in traps, and $61 \%$ of the variation in the density of recruiting seedlings. Recruitment failure occurred during the strong El Niño in 1998 when fruit was aborted. In a later study conducted on this species at seven sites spanning $50 \mathrm{~km}$ of coast in the same area over 9 months, fertilization success and seed production depended on pollen production $\leq 50 \mathrm{~m}$ away, which in turn, determined seed recruitment ( $\mathrm{F}=64.15<0.001$; Buckel et al. 2012). Male abundance also determined fertilization success, seed production and seedling recruitment $(Z=4.02, \mathrm{p}<0.001)$ in Phyllospadix scouleri at four to seven sites over 3 years across $90 \mathrm{~km}$ of the outer coast of the Olympic Peninsula, WA, USA (Shelton 2008). In the same paper, male abundance also determined fertilization success and seed production of Phyllospadix serrulatus, which was lower than for $P$. scouleri at the four sites investigated over 3 years. Recruitment failure of $P$. serrulatus occurred with only six seedlings recruiting during the entire study.
Coupling between reproduction and recruitment occurred in $63 \%$ of eight studies and two species of Zostera spp. from six papers (Table 1). Competition of seedlings with established shoots primarily determined the degree of coupling between reproduction and recruitment as well as the stronger coupling in annual than perennial or mixed populations. In a 2-year study conducted in Jindong Bay, Korea (Kim et al. 2014), an annual population allocated 80 to $90 \%$ of total production to seed production; 25 to $30 \%$ of the seeds occurred in the sediment seed bank; $28.2 \%$ of these seeds germinated and developed into seedlings; $30 \%$ of the newly recruited seedlings survived, and 93 and $96 \%$ of these seedlings ( 25.8 and $29.7 \%$ of all recruited seedlings) developed into reproductive shoots. In contrast, the perennial population allocated only 25 to $50 \%$ of total production to seed production; more of the seeds (30 and 46\%) occurred in the sediment seed bank likely because overwintering shoots trap the seeds limiting advection; fewer (8.6\%) of these seeds germinated and developed into seedlings; none of the seedlings flowered and fewer (3.2 and 4.4\%) of them survived to become adult shoots likely due to competition with mature shoots. Sexual reproduction contributed only 15 to $25 \%$ of total shoot production in the perennial population, whereas it completely maintained the annual population. Similarly, in a study conducted in China over 18 months (Xu et al. 2018), sexual reproduction was high in a mixed population of annual and perennial eelgrass at Swan Lake, the peak percentage of flowering shoots was high $(53.3 \%)$. Consequently, the potential seed output $\left(53,624\right.$ seeds $\left.\mathrm{m}^{-2}\right)$, peak seed bank density (552 seeds $\mathrm{m}^{-2}$ ) and seedling density were high (297 seedlings $\mathrm{m}^{-2}$ ). Recruitment from seedlings reached $50.5 \%$ and shoots from seedlings flowered. In contrast in a perennial population at Huiquan Bay, the peak percentage of flowering shoots was low (29\%), and consequently, the potential seed output was 
low $\left(29,000\right.$ seeds $\left.\mathrm{m}^{-2}\right)$, seed bank density was very low (254 seeds $\mathrm{m}^{-2}$ ) due to advection by waves and currents and recruitment from seedlings was very low (2.5\%). Reproduction and recruitment also were not coupled in six perennial stands of Zostera marina in Limfjorden, Denmark, over a year (Olesen 1999). Potential seed production per area was 8100 seeds $\mathrm{m}^{-2}$, and seedling density was $282 \mathrm{~m}^{-2}$ at the beginning of the reproductive season rapidly declining to only five seedlings $\mathrm{m}^{-2}$ by the end of the season due to shading by surrounding shoots.

Strong coupling occurred following die-offs or intensive grazing of established Zostera spp. beds in three studies (Table 1). After a total die-off of $Z$. marina from anoxia at the Thau Lagoon in the French Mediterranean Sea, flowering did not occur the first year of recolonization but reproductive effort and success were remarkably high during the second year when reproductive shoots accounted for $75 \%$ of total biomass and $79 \%$ of seedlings survived resulting in a fully reestablished bed just 9 months after germination of the seedbank (Plus et al. 2003). Similarly, Zostera capricorni in Moreton Bay, southeast Queensland, Australia, fully recovered in less than a year due to the high incidence of sexual reproduction after intensive grazing by dugongs denuded beds (Peterken and Conacher 1997). Flowering shoots peaked at $11.8 \%$ of all shoots, and seed germination peaked at $22 \%$ of all seeds, resulting in considerably higher seed production than previously reported. Strong coupling between reproduction and recruitment of $Z$. marina occurred following recolonization from the complete die-off caused by red tide in Jindong Bay on the southeast coast of Korea, but it was low the year before the disturbance and 2 years after the initial year of recovery due to competition of seedlings with established shoots (Lee et al. 2007). The year before the algal bloom, peak reproductive shoots accounted for $13 \%$ of the total shoot density, whereas they contributed $10 \%$ during the first year of recolonization and $20 \%$ the year after colonization. Consequently, potential seed production of 5500 seeds $\mathrm{m}^{-2}$ before the die-off dropped to 1300 seeds $\mathrm{m}^{-2}$ during the dieoff and then increased to 15,900 and 25,500 seeds $\mathrm{m}^{-2}$ in the two following years. The maximum seed density in sediments the first year after the die-off was only 200 seeds $\mathrm{m}^{-2}$, whereas it increased to 850 seeds $\mathrm{m}^{-2}$ and 1780 seeds $\mathrm{m}^{-2}$ in the next 2 years. About $16 \%$ of the seeds produced contributed to the seed bank the year after the algal bloom, but only 5 to $7 \%$ of them did during the next 2 years when the number of seeds produced was 10 to 20 times higher, likely due to advection or predation. Seedlings accounted for $100 \%$ of eelgrass shoots the first spring after the bloom but only $22.6 \%$ of the total shoot density before the bloom and $6 \%$ in the 2 years after the bloom when the eelgrass bed had completely recovered. Nearly all eelgrass seedlings that germinated after the bloom survived the first growing season after the die-off, and seedlings grew exponentially during the spring resulting in rapid recolonization of eelgrass.
Reproduction and recruitment were decoupled in populations of three other species of seagrasses in three papers (Table 1). Decoupling of reproduction and recruitment by wigeongrass, Ruppia maritima, in Long Lake, FL resulted from highly dynamic salinity and irradiance, which ranged from $10 \mathrm{psu}$ in the wet season to $>50 \mathrm{psu}$ in the dry season and $<2 \%$ median light transmission to the bottom $(<1.5 \mathrm{~m}$ deep) during persistent phytoplankton blooms (Strazisar et al. 2016). Reproductive shoots composed only $18 \%$ of total shoots and $11 \%$ of inflorescences bore seeds, producing a seed set of $\sim 2800$ viable seeds $\mathrm{m}^{-2}$. Seed bank densities were high $\left(>20,000 \mathrm{~m}^{-2}\right.$ ), but $85 \%$ of seeds germinated, leaving a small persistent seed bank, and most germinations did not successfully produce seedlings. Only $25 \%$ of intact seeds were viable with 2750 seeds $\mathrm{m}^{-2}$ entering the seed bank, which increased total seed bank viability from $<4$ to $\sim 20 \%$. The lack of a persistent seed bank, high germination rate and total vegetation mortality following reproduction indicated that the population was recruitment limited relying on reproductive events for population regeneration. At Pag-asa Island in the Philippine Kalayaan Island Group over one summer, 28\% of turtlegrass, Thalassia hemprichii, shoots produced flowers potentially yielding 130 seeds $\mathrm{m}^{-2}$, but seedling densities were only 27 seedlings $\mathrm{m}^{-2}$, suggesting substantial loss due to export of sexual propagules or seedling mortality (Rollon et al. 2001). At Magalluf Bay, Spain, over 4 years, flowering of Posidonia oceanica occurred only twice, likely due to the decadal warming trend in the Mediterranean (Diaz-Almela et al. 2009). During the first flowering event, only $2.0 \%$ of seagrasses and kelp produced inflorescences, fructification failed and sexual recruitment did not occur the following year. The second flowering event was intensive when $54 \%$ of the shoots flowered and massive fructification occurred (156 mature fruits $\mathrm{m}^{-2}$ ) but only three rooted seedlings were produced. Shoot mortality increased during summer as seawater warmed, especially during a heat wave, so that total recruitment was 4.5 times lower than mortality.

Coupling occurred in the one study on kelp. Castorani et al. (2017) determined that fluctuations in fecundity rather than dispersal primarily drove variation in connectivity and contributed substantially to metapopulation dynamics, recovery and persistence of the giant kelp, Macrocystis pyrifera, across 11 years and $900 \mathrm{~km}$ of coastline in southern CA, USA. A high-resolution ocean circulation model showed that high densities of spores and brief dispersal (hours to days) resulted in relatively small fluctuations in spore dispersal but very large fluctuations in patch-scale spore production.

\section{Brooders Releasing Swimming Competent Larvae with Short PLDs ( $\leq 1$ Week)}

Coupling in brooding colonial ascidians and sponges, which release swimming larvae that are competent to settle, occurred 
in $94 \%$ of 18 studies and $93 \%$ of 15 species and genera from 14 papers (Table 2; Fig. 3A). Statistics were reported in $50 \%$ of studies. A SRR with or without statistics was determined in five and eight studies, respectively, and a spatial SRR with or without statistics was determined in four and one study (Table 2). Coupling was common even though most studies were brief, averaging 1.4 years, and $67 \%$ were conducted at just one site, averaging 3.3 sites (Table 2). The rest of the studies were conducted at an average of eight sites spanning $408.3 \mathrm{~km}$. Coupling occurred in all nine studies that incorporated dispersal. Coupling of a total of six species in two papers was compared. Intervening stages between reproductive output and recruitment were quantified in most studies (Table 2). Adults were quantified in $89 \%$ of the studies, larvae and setters in $72 \%$, and reproductive output, recruitment and early postsettlement mortality in $61 \%, 56 \%$ and $50 \%$, respectively (Table 2; Fig. 5). Decoupling did not occur in ascidians or pocilloporid corals, and the one case of decoupling in the three studies on sponges likely resulted from advection and behaviorally regulated dispersal (Table 2).

Colonial ascidians are atypical in releasing relatively large, strongly swimming larvae that usually settle in minutes during daylight so that coupling and the causes of decoupling can be directly observed. These traits resulted in coupling in all 14 studies of 11 species from 11 papers (Table 2). Reproductive output explained $56 \%$ of the variation in recruitment $(\mathrm{p}<$ 0.001) of Aplidium stellatum (Gotelli 1987). Reproductive output and recruitment were even more strongly related $\left(\mathrm{R}^{2}\right.$ $=0.95, \mathrm{p}<0.05)$ in Ecteinascidia turbinata with $29 \%$ of larvae settling locally (Carballo 2000). The timing of larval release and settlement also were highly correlated $(r=0.86, p$ $=0.012$ ) in Didemnum candidum on coral reefs, accounting for $74 \%$ of the variation in settlement, as were the intervening stages of larval release and abundance $(r=0.87, p=0.010)$ accounting for $69 \%$ of the variation and larval abundance and settlement $(r=0.94, p=0.002)$ accounting for $92 \%$ of the variation in settlement (Hurlbut 1992). Larval release accounted for $37 \%(\mathrm{p}=0.001)$ of the variation in settlement of Podoclavella moluccensis (Davis 1989) with only $6.1 \%$ of larvae settling in the study area (Davis 1988) despite the brief larval duration (Davis and Butler 1989). The percentage of larvae settling in the study area was estimated by the daily number of larvae collected in larval traps as well as the number of embryos produced, the density and size of adult colonies, the proportion of each colony that brooded larvae and the number of larvae produced by each zooid. The number of larvae caught by traps was less than half that of the estimate based on the fecundity of adult colonies, perhaps because larval traps were not deployed over the entire period that larvae were released, potentially underestimating the percentage of larvae settling in the study area. This uncertainty and the brief larval duration of these larvae led me to tentatively conclude that coupling may have occurred. Coupling between adults and larval recruitment of four ascidians (Ascidia nigra, $\mathrm{F}=9.82, \mathrm{p}=0.002$, Botryllus planus, $\mathrm{F}=3.17, \mathrm{p}=0.031$, Didemnum psammathodes, $\mathrm{F}=6.27, \mathrm{p}=0.001$ and Symplegma viride, $\mathrm{F}=8.16, \mathrm{p}<0.001$ ) was indicated by the clumped distributions on prop roots of mangroves among four neighboring channels due to larval supply and low water flow rather than postsettlement mortality (Bingham 1992).

Individual larvae were tracked in five of the 14 studies on ascidians revealing their fate, which provided our only direct measure of the magnitude and causes of larval mortality in the sea (Morgan 1995; White et al. 2014). Mortality was greater in the plankton than after settlement in only half of these studies even though it is widely believed that planktonic mortality generally is much greater (Morgan 1995; Strathmann et al. 2002). Larval mortality during the brief larval phase differed considerably among species affecting the degree of coupling between reproductive output and settlement. Larval mortality was zero for Didemnum molle larvae (Olson 1985), 11\% for P. moluccensis (Davis and Butler 1989), 29\% for Diplosoma similis (Stoner 1990) and 87\% for Lissoclinum patella (Olson and McPherson 1987). In a second study on D. similis, larval mortality ranged from 0 to $30 \%$ depending on whether larvae were released at the reef flat or $6 \mathrm{~m}$ deep (Stoner 1992). Predation was the main cause of larval mortality. Mortality of $L$. patella larvae was entirely due to predators, more than three-quarters by fishes and the rest by corals and zoanthids (Olson and McPherson 1987). Larval morality of $P$. moluccensis also was entirely due to predation, but solely by corals (Davis and Butler 1989). Mortality of $D$. similis larvae was due to predation by corals, entanglement in mucus or mucilaginous larvacean houses or poor attachment to algal turf during settlement (Stoner 1990, 1992).

Postsettlement mortality also differed considerably among species of ascidians affecting the degree of coupling between larval settlement and density of adults. Postsettlement mortality appeared to be low in six species with the density of settlers largely determining the distribution and abundance of adult colonies, including D. molle, P. moluccensis, A. nigra, B. planus, D. psammathodes and S. viride (Olson 1985; Davis 1988; Bingham 1992). For P. moluccensis, settlement explained $86 \%$ of the variation in recruitment 1 month later and the density of recruits and adult colonies were well correlated in two consecutive years. Density-dependent mortality was low with the mortality and density of recruits being weakly correlated in the first year and not correlated in the second year. Planktonic mortality was higher than benthic mortality with only $6.1 \%$ of larvae surviving and $14.4 \%$ of recruits surviving to adulthood 11 months later, and overall mortality was high with only $0.56 \%$ of larvae released surviving to sexual maturity. In contrast, postsettlement mortality was high in two species of ascidians. Postsettlement mortality of E. turbinata was $95.9 \%$ with only $1.3 \%$ of larvae produced becoming adults (Carballo 2000). At least $90 \%$ of all newly 


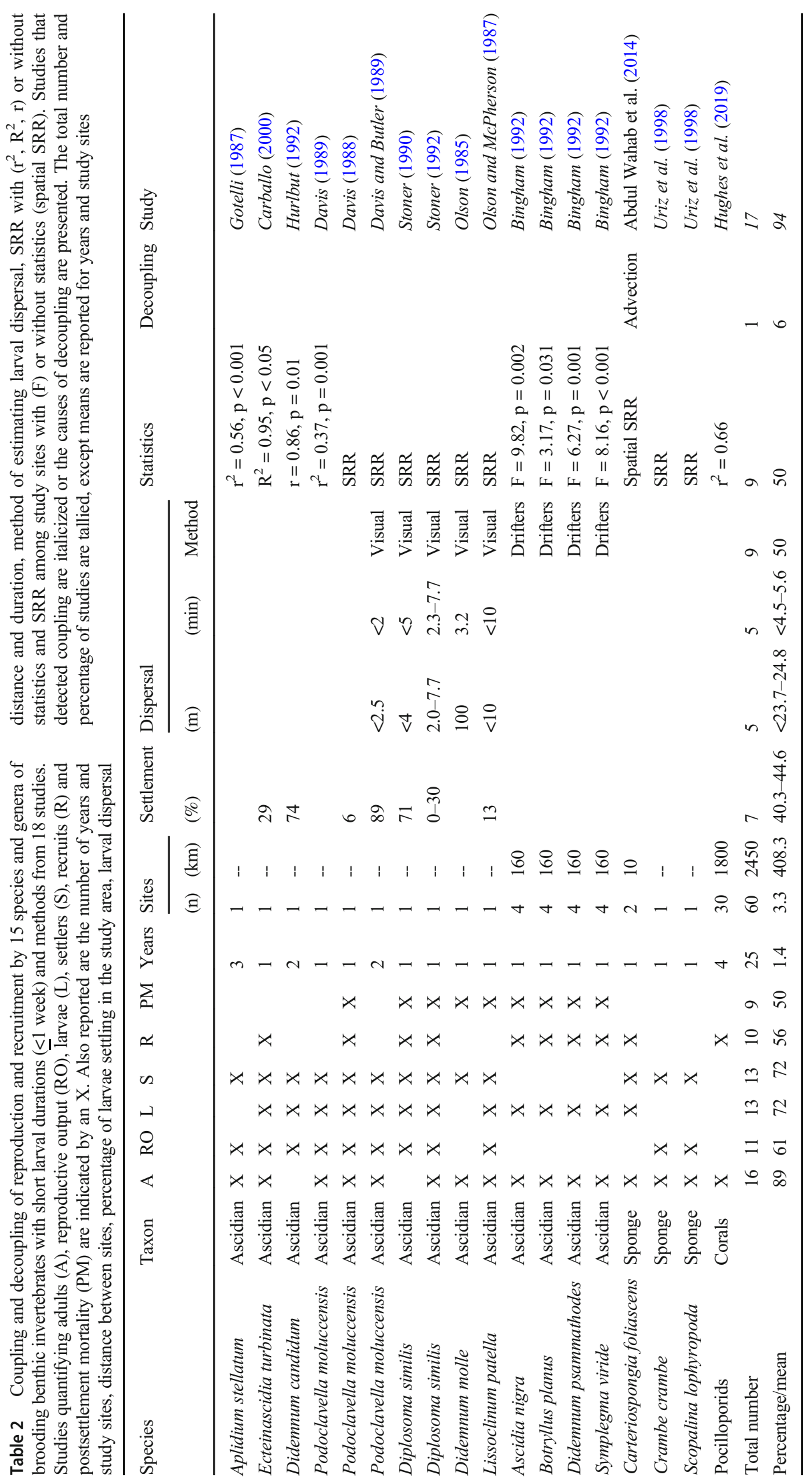



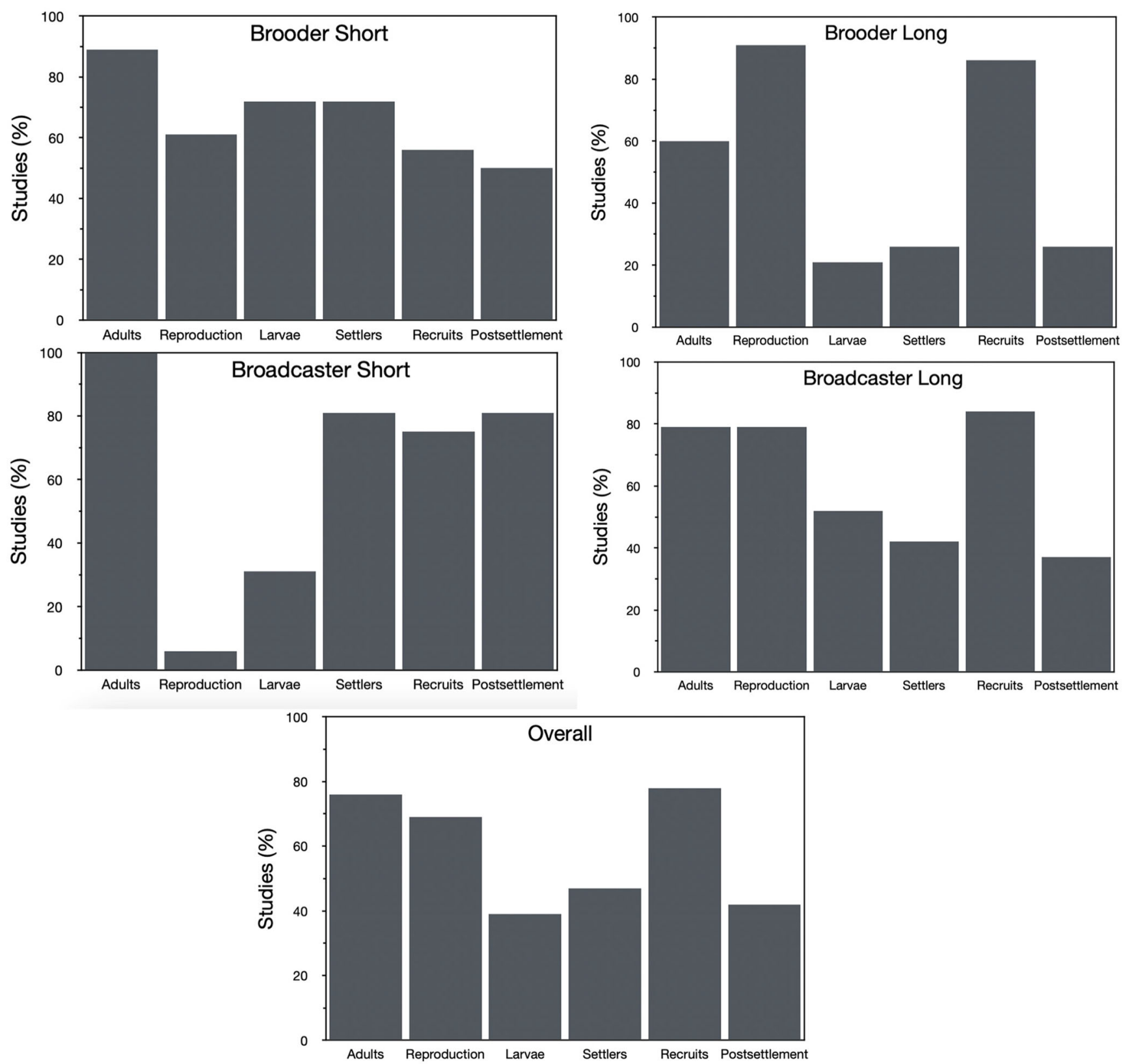

Fig. 5 Percentage of reviewed studies on benthic animals that quantified the reproductive, larval, settlement, recruitment and postsettlement phases of the life cycles of brooders with short ( $\leq 1$ week; 18 studies)

and long (>1 week; 43 studies) planktonic larval durations (PLDs), broadcasters with short (16 studies) and long PLDs (19 studies) and overall (112 studies)

settled colonies of $D$. similis died within a month, and benthic mortality was much higher than planktonic mortality indicating that postsettlement mortality strongly regulated populations (Stoner 1990).

Visually tracking larvae of four species of ascidians over coral reefs revealed that larvae settled just meters away from parent colonies resulting in essentially closed populations. Released larvae initially swam toward the surface where faster currents ensured dispersal before swimming to the bottom thereby avoiding inbreeding and crowding while limiting dispersal (Strathmann et al. 2002; Burgess et al. 2016). Didenum molle larvae swam $2.5 \mathrm{~cm}^{-1 \mathrm{~s}}$ upstream in the slow flow occurring in the lee of coral heads or within $10 \mathrm{~cm}$ of the bottom, and invariably settled downstream, in $190 \mathrm{~s}$ despite being capable of swimming for $2 \mathrm{~h}$ (Olson 1985). Because reproductive output and settlement were coupled, the number of settlers predictably depended on the numbers of adults upstream (Olson 1985). Newly settled larvae and juveniles were not crowded, suggesting that larval recruitment was limited. Lissoclinum patella larvae usually settled less than $10 \mathrm{~m}$ from parents within $10 \mathrm{~min}$ despite being capable of swimming $1 \mathrm{~h}$ (Olson and McPherson 1987). Most P. moluccensis larvae 
(80\%) settled within $2.5 \mathrm{~m}$ of parents after swimming for less than 2 min, despite being capable of swimming for $2 \mathrm{~h}$, and they preferred to settle in bare space where survival was high (Davis and Butler 1989). Most D. similis larvae swam less than $5 \mathrm{~min}$ and toward the reef at $5.3^{-1 \mathrm{~s}}$ in the lee of coral heads thereby dispersing less than $4 \mathrm{~m}$, even though metamorphosis can be delayed for $1 \mathrm{~h}$ (Stoner 1990). In the second study on D. similis (Stoner 1992), larvae dispersed 2.0 to 7.7 $\mathrm{m}$ over 140 to $466 \mathrm{~s}$ depending on whether larvae were released at 2 or $6 \mathrm{~m}$.

Coupling also was evident in the only study on brooding pocilloporid corals and in $66 \%$ of three studies and species of brooding sponges from two papers (Table 2). In a study spanning the Great Barrier Reef (Hughes et al. 2019), mass mortality of corals caused by thermal stress from global warming along the northern two-thirds of the reef during two consecutive years led to a $63.5 \%$ decline of pocilloporids and other brooders $(\mathrm{PLD}<1 \mathrm{~d}$ ) in recruitment the following year compared to the three previous years while stock-recruitment relationships remained strong $\left(\mathrm{r}^{2}=0.66\right)$. Larval durations of brooding sponges range from several hours to several days (Abdul Wahab et al. 2014), potentially dispersing larvae farther than colonial ascidians depending on the species. Body size, fecundity and growth rate of Carteriospongia foliascens were greater in a bay with larger waves than smaller waves on the Great Barrier Reef over 24 months, but recruitment was very low in both bays (six and one individual), indicating that decoupling occurred (Abdul Wahab et al. 2014). In a second study, differences in larval behavior regulated dispersal of two species of sponges in the Mediterranean (Uriz et al. 1998). The number of larvae released by Crambe crambe was about 20 times higher than Scopalina lophyropoda, but the number of recruits was only 3.5 times higher. Larval durations of the two species ranged from 24 to $72 \mathrm{~h}$ and the larval behaviors differed. Crambe crambe larvae swam toward the surface, where faster currents dispersed them several meters away, and they delayed crawling on the substrate. Larvae of S. lophyropoda dispersed even less by staying near the bottom and crawling early. Minimal dispersal by both species indicates that larval release and settlement were coupled.

\section{Broadcast-Spawners Releasing Eggs Developing into Swimming Larvae with Short PLDs $(\leq 1$ Week)}

Coupling was less common, more variable and harder to detect in broadcast-spawning corals, a bryozoan and a solitary ascidian than brooders with short PLDs. Coupling was evident in $50 \%$ of 16 studies and $57 \%$ of 14 species and genera from six papers (Table 3; Fig. 3A). Statistics were reported in $44 \%$ of studies. A SRR with or without statistics was determined in three and eight studies, respectively, and a spatial SRR with statistics was determined in four studies (Table 3). Coupling occurred even though most studies were brief, averaging 2.3 years, and $50 \%$ were conducted at just one site, averaging 10.5 sites (Table 3 ). The rest of the studies were conducted at an average of 21 sites that spanned $618.8 \mathrm{~km}$ (Table 3). A hierarchical sampling design was incorporated in two studies on acroporid corals. Coupling occurred in $100 \%$ of the six studies that incorporated dispersal. Coupling by a total of 12 species in two papers was compared. Adults were quantified in $100 \%$ of 16 studies, settlers and postsettlement mortality in $81 \%$, recruits in $75 \%$, and larvae and reproductive output in just $31 \%$ and $6 \%$, respectively (Table 3; Fig. 5). Decoupling occurred in $56 \%$ of the 16 studies likely due to temperature disrupting spawning synchrony $(89 \%)$ and larval advection $(11 \%)$ in the nine instances of decoupling (Table 3 ).

Coupling occurred in $27 \%$ of 11 studies and $33 \%$ of nine species and genera of corals from six papers (Table 3 ). Fecundity was a major determinant of larval recruitment at large $(\geq 700 \mathrm{~km})$ but not small $(\leq 10 \mathrm{~km})$ scales for three species of corals, Acropora hyacinthus, Acropora cytherea and Acropora millepora, that spawn synchronously over a few days with larvae settling 3-7 days later (Hughes et al. 2000). A hierarchical sampling design consisting of 33 reefs in five sectors spaced 250-400 km apart along the length of the Great Barrier Reef, Australia, revealed that fecundity varied from 15 to $100 \%$ explaining $72 \%$ of the variation in recruitment of the three species combined over two breeding seasons. Recruitment rates were high where the proportion of gravid colonies approached $100 \%$, which enhanced fertilization. In a subsequent study spanning the Great Barrier Reef (Hughes et al. 2019), mass mortality of acroporids and other broadcast-spawners caused by thermal stress from global warming along the northern two-thirds of the reef during two consecutive years resulted in a $93 \%$ decline in recruitment the following year compared to the three previous years while stock-recruitment relationships remained strong $\left(\mathrm{r}^{2}=0.52\right)$.

Combining demographic surveys of Acropora spp. at 80 sites in the Palau archipelago with a hydrodynamic model indicated that reefs with the highest cover of coral and densities of juveniles also had the highest simulated larval retention and recruitment (Golbuu et al. 2012). Considerable local retention occurred at all sites within 3 days of spawning, which is long enough for some larvae to settle. However, at longer time scales, simulated larvae were retained and selfrecruitment occurred in the southern lagoon coupling stock and recruitment, and they were flushed from the northern lagoon decoupling stock and recruitment. Overall, the percentage of coral cover and the density of self-seeding estimated by the oceanographic model were related $\left(\mathrm{R}^{2}=0.19, \mathrm{p}=0.002\right)$

Nozawa et al. (2006) did not detect coupling between stock and recruitment of eight species of broadcasting scleractinian corals at high latitudes over three reproductive seasons. Although fecundity was high (76.7-100\%), settlement after spending 3-7 days in the plankton was low $\left(2\right.$ recruits $\mathrm{m}^{2}$ ) because spawning synchrony was disrupted by unusually low 


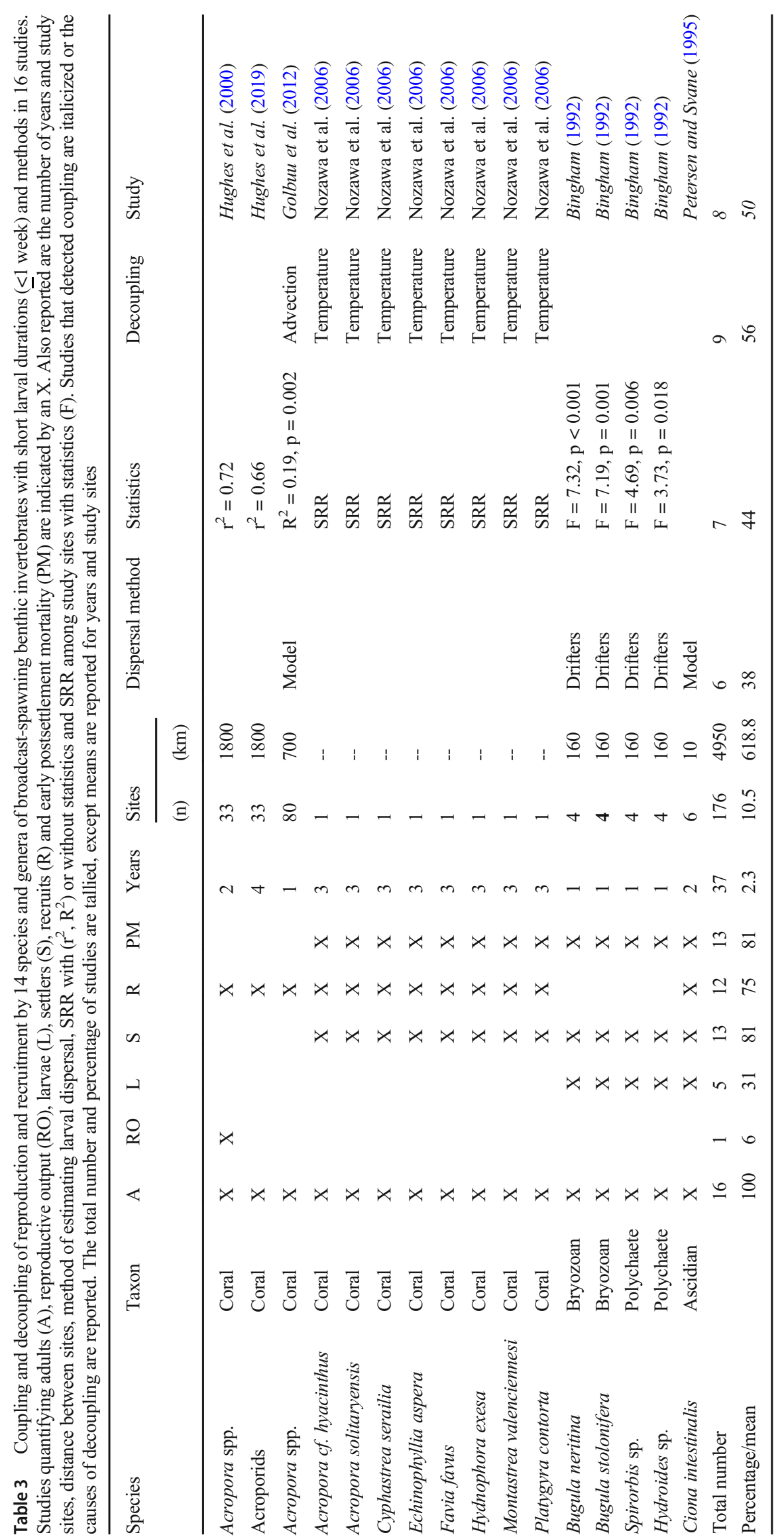


or variable water temperature. Postsettlement mortality over 3 months was high (88-100\%) but comparable to other studies conducted at both low and high latitudes.

Coupling between adults and larval recruitment of two bryozoans (Bugula neritina, F = 7.32, $\mathrm{p}<0.001$ and Bugula stolonifera, $\mathrm{F}=7.19, \mathrm{p}=0.001, \mathrm{PLD}<1$ day) and two polychaetes (Spirorbis sp., F $=4.69, \mathrm{p}=0.006, \mathrm{PLD}=15 \mathrm{~min}-2 \mathrm{~h}$ and Hydroides sp., $\mathrm{F}=3.73, \mathrm{p}=0.018, \mathrm{PLD}=5-8$ days) was indicated by the clumped distributions on prop roots of mangroves among four neighboring channels due to larval supply and low water flow rather than postsettlement mortality. Fecundity alone accounted for roughly $10 \%$ of recruitment by the solitary ascidian, Ciona intestinalis, in a fjord, and a hydrodynamic model estimated that larvae dispersed less than $11 \mathrm{~m}$ during their 2-10-day PLD with larval recruitment being restricted to a cove (Petersen and Svane 1995). Dispersal was limited because only half of the larvae hatching from eggs escaped to the plankton while the rest remained in mucus strings of fertilized eggs on the bottom.

\section{Brooders Releasing Swimming Precompetent Larvae with Long PLDs (>1 Week)}

Coupling was evident in $63 \%$ of 43 studies and $61 \%$ of 27 species and genera of brooding coral reef fishes, shrimp, barnacles, lobsters and crabs with long PLDs from 34 papers (Table 4; Fig. 3A). Statistics were reported in $70 \%$ of studies. A SRR with or without statistics was determined in 30 and five studies, respectively, and a spatial SRR with and without statistics was determined in two and one study (Table 4). Studies were much longer, averaging 9 years, and conducted at more sites, averaging 8.7 sites spanning $161 \mathrm{~km}$ (Table 4) than for seagrasses and kelp and animals with short PLDs. A hierarchical sampling design was incorporated in two studies from different papers. Coupling occurred in $67 \%$ of the six studies that incorporated dispersal. Coupling of a total of eight species in two papers was compared. Reproductive output, recruitment and adults were quantified in $91 \%, 86 \%$ and $60 \%$ of the studies, whereas settlement, early postsettlement mortality and larvae were quantified in only $26 \%, 26 \%$ and $21 \%$ of them, respectively (Table 4; Fig. 5). Decoupling occurred in $28 \%$ of the studies due to advection (50\%) and food limitation $(33 \%)$ in the plankton and thermal stress disrupting reproduction in $17 \%$ of the 12 instances of decoupling (Table 4).

Coupling occurred in $33 \%$ of 15 studies and $31 \%$ of 12 species of pomacentrids and a labrid from 10 papers (Table 4). Damselfishes and anemonefishes are demersal and territorial brooding 50 to 1000 eggs per nest and hatching large larvae ( 2 to $4 \mathrm{~mm}$ long) after 2 to 7 days that develop for a week to a month in the plankton, depending on the species. Intra-annual coupling between larval production and settlement was investigated for four species of damselfishes by capitalizing on synchronous spawning and hatching and precise larval durations from daily otolith rings. Coupling was detected for $50 \%$ of four of these species and decoupling or weak coupling occurred for the other two species (Table 4). Spawning and settlement of Stegastes partitus occurred monthly for 3 years, the larval duration was 37 days with little variation and consequently, recruitment consistently occurred synchronously 5 weeks after spawning as determined by timeseries analyses (Robertson et al. 1988). Larval production also drove temporal patterns of larval supply and recruitment of Pomacentrus amboinensis after spending 23 days developing in the plankton over two reproductive seasons (cross-correlations $r=0.580, r=0.590$; Meekan et al. 1993). The magnitude of spawning and larval recruitment was not correlated for either species. In contrast, a temporal link between reproductive output and larval recruitment of Pomacentrus vaiuli was weak (cross-correlations $r=0.30, r=0.27$ ) during two consecutive years at one location and it was not significant at a second location due to low spawning the first year of the study and a cyclone during the second year (McIlwain 2002). A temporal link between reproductive output and larval recruitment was not detected by spectral analysis for Dascyllus albisella over 1 year because recruits originated elsewhere (Danilowicz 1997).

Coupling of reproduction and larval recruitment was detected among metapopulations in $27 \%$ of 11 studies and $22 \%$ of nine species of fishes from six papers (Table 4). Coupling was detected in three studies of two species of anemonefishes. Using parentage analysis, $18 \%$ of Amphiprion polymnus recruits were spawned from eight populations across $30 \mathrm{~km}$ of coast in Papua New Guinea with $7 \%$ of them returning to natal sites, $11 \%$ recruiting to other sites and $25 \%$ dispersing less than $3 \mathrm{~km}$ (Saenz-Agudelo et al. 2011). Including information on fecundity and longevity revealed that self-persistence was likely for five of these populations with the number of recruits replacing adults ranging from 33.4 to $7 \%$ (Burgess et al. 2014). Two studies linked female size, the number of eggs spawned and the number of recruits by combining field estimates of egg production, DNA profiling to track individuals through time and parentage analysis to assign offspring to their parents for all members of small metapopulations of A. polymnus and Amphiprion chrysopterus over 2 years (Beldade et al. 2012; Saenz-Agudelo et al. 2015). Large A. chrysopterus females contributed more recruits to the local population than small females (Beldade et al. 2012).

In contrast, spatial coupling was not detected for six species of damselfishes in two studies and a labrid in a third study (Table 4). Johnson et al. (2018) quantified reproductive output, postsettlement survival and growth, lifetime egg production, demographic connectivity by parentage analysis and self-persistence of a of metapopulation of $S$. partitus at four islands in the Bahamas and found that $13.3 \%$ of recruits returned to natal islands, local retention was high $(41 \%)$ on 


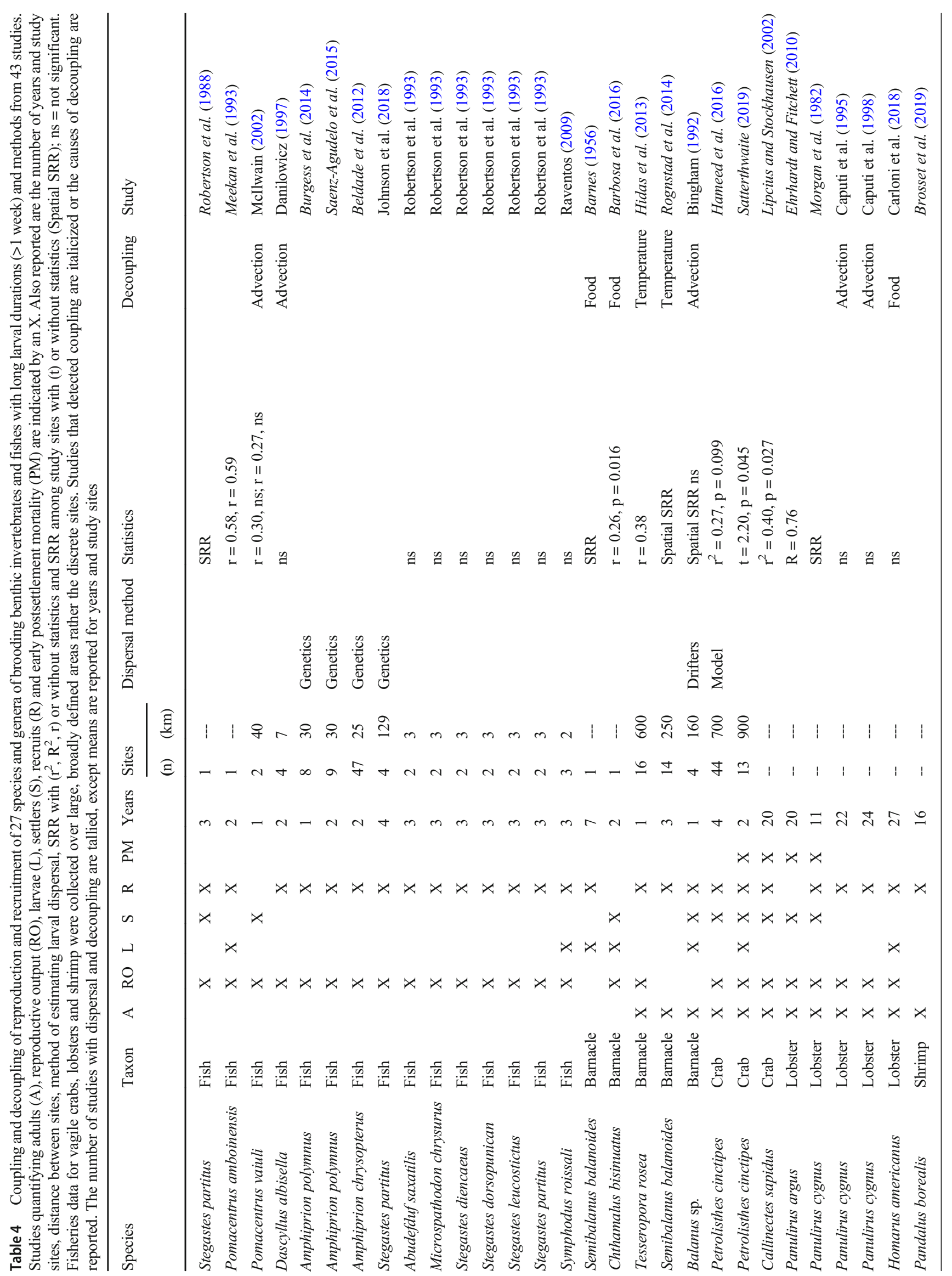




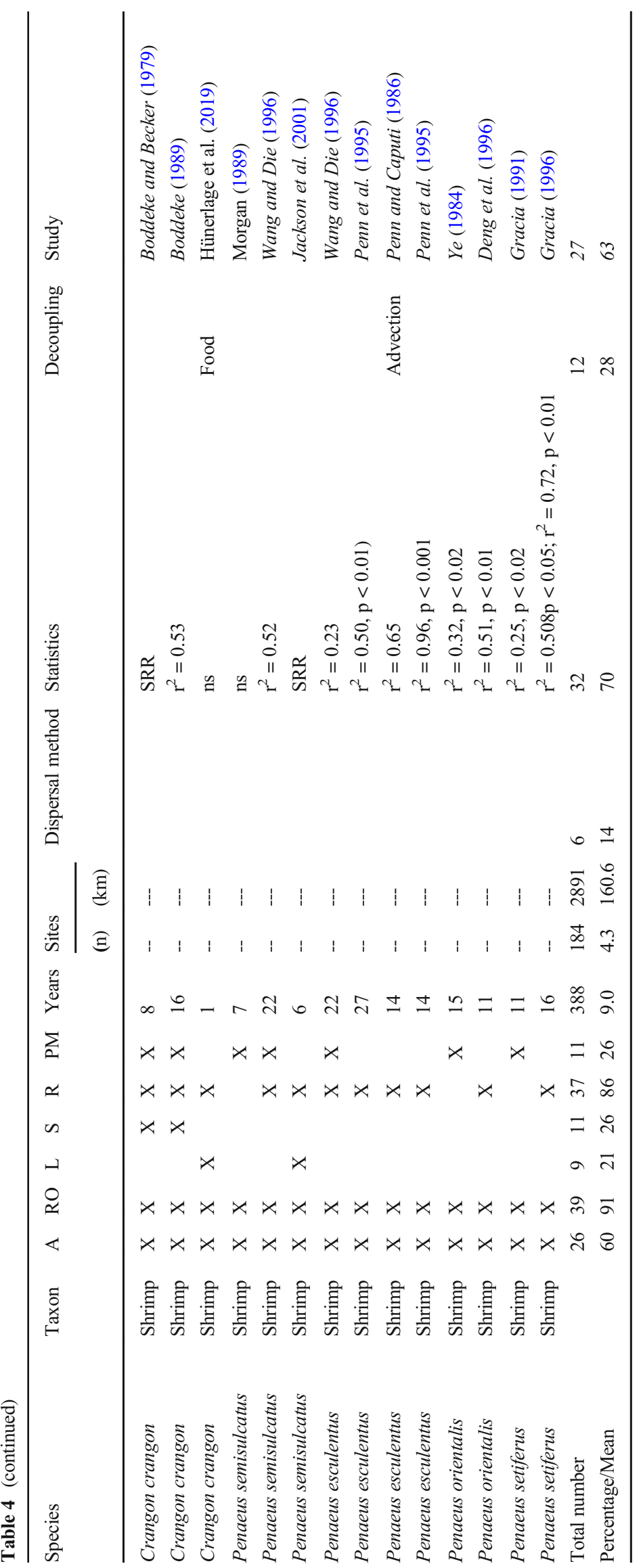


one island and larval connectivity was appreciable (1.6\%) even between islands spaced $129 \mathrm{~km}$ apart. Lifetime offspring production varied fivefold among islands, and the contribution of each island to the long-term growth of the metapopulation depended on both larval production and connectivity, although the metapopulation could not grow without larval input from elsewhere. Robertson et al. (1993) monitored spawning of Abudefduf saxatilis, Microspathodon chrysurus, Stegastes diencaeus, Stegastes dorsopunicans, Stegastes leucostictus and S. partitus monthly for 1-3 years and recruitment monthly for 7-10 years at Punta de San Blas on the Caribbean coast of Panama. Variation in recruitment was at least 1.5-3 and as much as 4-20 times greater than spawning and not correlated in any species. At three sites in the northwestern Mediterranean Sea over 3 years, the number of spawners and the number of nests of the labrid, Symphodus roissali, were coupled but not the number of nests and recruits or young of the year 3 months after settlement, although the number of young of the year was related to the number of reproductive adults the following year (Raventos 2009).

Coupling between reproduction and recruitment occurred in $80 \%$ of five studies and $75 \%$ of three species and a genus of barnacles from five papers (Table 4). Instances of decoupling from food limitation, thermal stress or advection occurred in all five studies. In a classic study conducted in the Fairlie Channel, Scotland (Barnes 1956), coupling for Semibalanus balanoides occurred in 7 years when diatoms were plentiful but not in 3 years when they were scarce (Fig. 6). Similarly, daily sampling of larval release, postlarvae and settlers of Chthamalus bisinuatus on tropical shores for 2 years demonstrated coupling among all three phases of reproduction (cross-correlation: larval release-larval supply $\mathrm{r}=0.329, \mathrm{p}=$ 0.001 ; larval supply-settlement $r=0.351, p=0.002$; larval release-settlement $r=0.261, p=0.016$ ), provided that phytoplankton was sufficient to complete the 11-day larval period in mesooligotrophic waters (Barbosa et al. 2016). Large-scale studies on two species detected regional but not small-scale coupling, likely because stressful temperatures disrupted reproduction at small scales. Surveying $600 \mathrm{~km}$ of the southeast coast of Australia using a hierarchical sampling design four times per year, determined that the density of adult Tesseropora rosea explained $38 \%$ of the variance in recruits with the densities of recruits mirroring those of adults across four 70 to $110 \mathrm{~km}$ sectors that were spaced 30 to $100 \mathrm{~km}$ apart but not at smaller scales (Hidas et al. 2013). However, fecundity was not correlated with either the densities of adults or recruits. Adult and recruit densities markedly declined toward the southern range limit where only $6 \%$ of adults contained mature embryos, perhaps due to the cold or too few adults to copulate, while the low settlement was most likely due to low larval supply when the Eastern Australian Current weakened and coastal eddies formed on the southeast corner of Australia
Fig. 6 Numbers of early-stage larvae (Stages I-III), late-stage larvae (Stages IV-VI) and postlarvae (cyprids) of the barnacle, Semibalanus balanoides, collected daily from the plankton throughout the reproductive season of two consecutive years in the Fairlie Channel, Scotland. Larvae developed and settled successfully when diatom food was plentiful in 1950 but not in 1951 when diatoms were scarce, decoupling reproductive output and settlement (from Levinton (1995), redrawn from Barnes (1956))

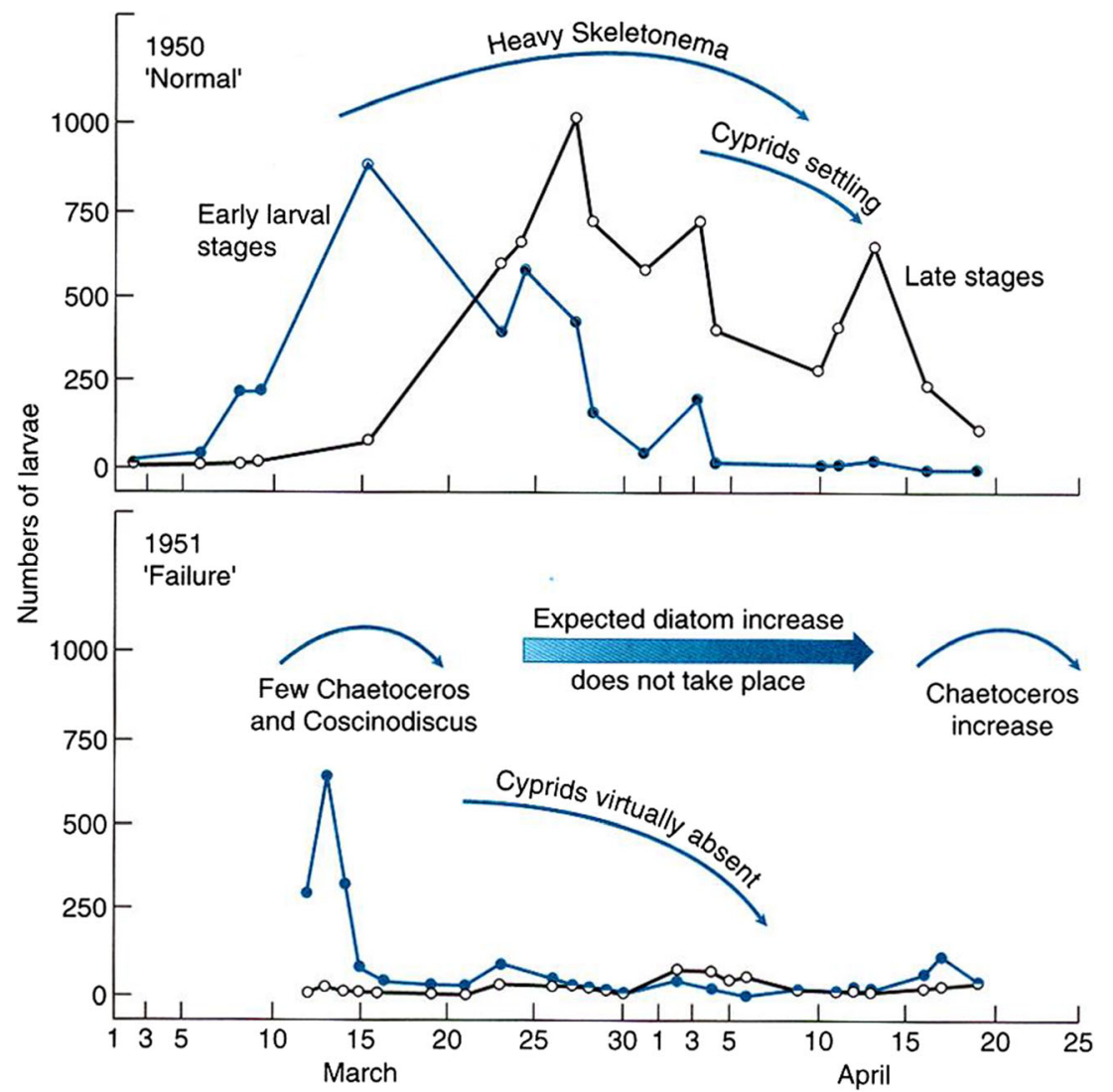


(Hidas et al. 2013). Similarly, S. balanoides populations in Southwest England were regulated by adult input into the larval pool at a regional scale but not at a local scale over 3 years (Rognstad et al. 2014). Warm temperatures limited reproduction, recruitment and adult densities since the 1930s. Coupling was not apparent for Balanus sp. on prop roots of mangroves among four neighboring channels due to larval advection and postsettlement mortality (Bingham 1992).

Coupling occurred in all three studies and two species of crabs (Table 4). Coupling occurred in the sedentary, intertidal porcelain crab, Petrolisthes cinctipes, during two large-scale studies conducted on an open coast in the upwelling system of northern CA, USA. Hameed et al. (2016) found (1) larval production and settlement of $P$. cinctipes per square meter of habitat were weakly coupled in 11 populations $\left(r^{2}=0.27, p=\right.$ 0.099 ) and (2) limited connectivity by using a Bayesian modeling approach based on measured production and settlement estimates for all 44 known populations spanning $700 \mathrm{~km}$ and a fitted larval mortality rate. Larvae were estimated to disperse $6.9 \mathrm{~km}( \pm 25.0 \mathrm{~km} \mathrm{SD})$ from natal populations after spending approximately 6 weeks in the plankton, in contrast to a prior dispersal estimate of $153.9 \mathrm{~km}$ based on currents and larval duration and behavior. Satterthwaite (2019) found coupling between fecundity and recruitment of $P$. cinctipes across 13 sites spanning $900 \mathrm{~km}$ and five of the sites for two consecutive years; sites with high total reproductive output also had high recruitment (Generalized Linear Mixed Effects Model $\left.t_{(1,14)}=2.20, p=0.045\right)$. Wave-exposed sites had more habitat for reproductive females and recruits, even though densities of recruits were low due to the difficulty that postlarvae have crossing the surf zone of these steep reflective shores.

The remaining species of brooders were fished commercially, including crabs, lobsters and shrimps, and stockrecruitment relationships were determined using fisheries data (Table 4). The blue crab, Callinectes sapidus, releases larvae from the mouths of estuaries, larvae emigrate to the outer continental shelf, metamorphose to postlarvae and then immigrate to nursery habitat in estuaries after spending 4-6 weeks in the plankton. Despite the long larval migration, Lipcius and Stockhausen (2002) detected significant positive relationships between spawning stock and larval abundance, spawning stock and postlarval recruitment $\left(\mathrm{r}^{2}=0.40, \mathrm{p}=0.027\right)$, and spawning stock and female size within spawning grounds over 13 years and lower-bay tributaries over 20 years. During this period, mean abundances of all four of these stages of the life cycle consistently and substantially declined. During the last 8 years of the study, (1) spawning stock abundance declined by $81 \%$, female size by $8 \%$ and spawning stock biomass by $84 \%$, (2) mean size at maturity diminished by $9 \%$ and (3) larval abundance and postlarval recruitment were lower by an order of magnitude than earlier years. These decreases occurred over less than 2 years, indicating a phase shift brought about by poor recruitment, despite high spawning stock and larval abundance, combined with high fishing and natural mortality.

For lobsters, coupling occurred in two (40\%) of five studies and two $(67 \%)$ of three species from five papers (Table 4$)$. Coupling was detected for the Caribbean spiny lobster, Panulirus argus, in the Florida Keys, USA, over 20 years, even though larvae develop in the plankton for about a year (Ehrhardt and Fitchett 2010). The abundance of spawning stock and postlarvae were highly correlated $(R=0.76)$ with a 12-month delay, indicating self-recruitment. Both wind stress and the seasonal formation of gyres and meanders from coastal currents may have retained larvae in the region for up to 8 months while southeasterly wind enhanced larval retention in the east-west oriented Lower Florida Keys and larval advection by Ekman transport in the southwest-northeast oriented Upper Keys (Lee et al. 1992). The North Atlantic Oscillation affected the spawning stock-recruitment relationship with settlement decreasing $36 \%$ and spawning stock decreasing $57 \%$ over the years, whereas recruitment from postlarval to pre-adult stages (first year) were not linked, indicating little density-dependent mortality. There also was a strong recruit-stock relationship $(R=0.77)$ with postsettlement mortality being correlated with changes in the Caribbean Mean Sea Level (CMSL); a higher CMSL decreased recruitment $(R=0.998)$ and a lower CMSL increased recruitment $(R=0.956)$.

Three studies were conducted on stock-recruitment relationships of the western rock lobster, Panulirus cygnus, along the coast of Australia (Table 4). Morgan et al. (1982) found a relationship between spawning stock and settlement of postlarvae at coastal sites over 11 years, even though larvae develop in the plankton for 9-11 months. A Ricker model also showed strong compensatory density-dependent mortality with an inverse relationship between settlement and spawning stock. Two subsequent studies did not detect a stockrecruitment relationship at three sites in western Australia over 21 years (Caputi et al. 1995) as well as over two more years (Caputi et al. 1998); the Leeuwin Current and westerly winds were the main determinants of postlarval settlement rather than spawning stock alone.

Coupling between reproductive output and larval recruitment was not found over 27 years for American lobster, Homarus americanus, which develop in the plankton for a year in the Gulf of Maine, USA, even though spawning stock, larvae, postlarvae and young-of-year were all surveyed (Carloni et al. 2018). Spawning stock biomass and first stage larvae were highly correlated $(r=0.56, p=0.002)$ as were postlarvae and young-of-year $(r=0.52, p=0.006)$. However, first stage larvae and postlarvae were decoupled $(r=-0.16, p$ $=0.414$ ), as both declined along with their favored food, the copepod Calanus finmarchicus.

For shrimps, coupling occurred in $87 \%$ of 15 studies and all six species from 13 papers (Table 4). In the northern shrimp, 
Pandalus borealis, Generalized Additive Models showed that stock and recruitment were related and varied with conditions in the plankton rather than the abundance of predatory fishes in the Gulf of St. Lawrence over 16 years (Brosset et al. 2019). A clear relationship $\left(r^{2}=0.53\right)$ between the densities of ripe eggs and catch of the brown shrimp, Crangon crangon, a few months later was detected along the coast of the Netherlands over 15 years even though larvae spend a month developing in the plankton (Boddeke and Becker 1979; Boddeke 1989). In contrast, no relationship between reproduction and larval recruitment was evident for $C$. crangon during weekly sampling of adults, ovigerous females, larvae and recruits throughout one reproductive season in the inner German Bight, likely due to food limitation in the plankton (Hünerlage et al. 2019).

Many studies on stock-recruitment relationships have been conducted on penaeid shrimp, which live 1-2 years, spawn offshore and recruit as postlarvae to estuaries after spending 2-3 weeks developing in the plankton (Table 4). Ye (2000) conducted a meta-analysis of stock-recruitment relationships for eight studies on four species and found that recruitment was related to the abundance of spawners overall. Individual stock-recruitment relationships were not significant for one study on Penaeus semisulcatus in Kuwait (Morgan 1989) and were significant for the other seven studies on P. semisulcatus $\left(\mathrm{r}^{2}=0.52\right)$ and Penaeus esculentus $\left(\mathrm{r}^{2}=\right.$ 0.23 ) in Northern Australia (Wang and Die 1996), P. esculentus in Shark Bay, Australia $\left(r^{2}=0.50, p<0.01\right.$, Penn et al. 1995), Penaeus orientalis in two studies in China $\left(r^{2}=0.32, p<0.02\right.$, Ye 1984; $r^{2}=0.51, p<0.01$, Deng et al. 1996) and Penaeus setiferus in the southwestern Gulf of Mexico $\left(r^{2}=0.25, p<0.02\right.$, Gracia 1991). Beyond the meta-analysis, Gracia (1996) extended his time series for five more years and continued to detect stock-recruitment relationships for two cohorts $\left(r^{2}=0.508, p<0.05 ; r^{2}=0.72, p<0.01\right)$ of $P$. setiferus over 17 years. Penn and Caputi (1986) documented a stock-recruitment relationship (multiple correlation coefficient 0.65) for P. esculentus in Exmouth Gulf, Western Australia over 14 years, except during 2 years with severe cyclones, and the relationship improved (multiple correlation of $0.96, \mathrm{p}<0.001$ ) after adding six more years of data (Penn et al. 1995).

Since the meta-analysis, Jackson et al. (2001) comprehensively surveyed the abundance of eggs, larvae, juveniles and adults of $P$. semisulcatus in the Gulf of Carpentaria for 6 years and determined that the relationship between (1) egg production and recruitment was good, (2) egg production and larval density was poor and (3) larval and postlarval density was better. Hence, rates of egg production and early larval survival appeared to be important determinants of recruitment success. Biophysical models revealed how spawning stockrecruitment relationships of penaeid shrimp could be improved by identifying offshore spawning areas that contribute larvae to estuarine nursery grounds in Australia (Rothlisberg et al. 1996; Crocos and van der Velde 1995; Condie et al. 1999; McLeay et al. 2016).

\section{Broadcast-Spawners Releasing Eggs Developing into Swimming Larvae with Long PLDs (>1 Week)}

There were fewer examples of coupling between reproduction and recruitment for species of broadcast-spawners than brooders with long larval durations, including mussels, clams, polychaetes and an oyster, scallop, abalone, bryozoan and urchin. Coupling was evident in $42 \%$ of 19 studies and $50 \%$ of 16 species and genera from 15 papers (Table 5; Fig. 3A). Statistics were reported in just $21 \%$ of studies. A SRR with or without statistics was determined in four and six studies, respectively, and a spatial SRR with and without statistics was determined in one and four studies (Table 5). Like brooders with long PLDs, studies were longer, averaging 7 years, and conducted at more sites, averaging 7.3 sites that spanned $69.7 \mathrm{~km}$ (Table 5), than for seagrasses, kelp and animals with short PLDs. A hierarchical sampling design was incorporated in two studies from different papers. Coupling occurred in $40 \%$ of the five studies that incorporated dispersal. Coupling of a total of seven species in three papers was compared. Recruits were quantified in $84 \%$ of the 19 studies, adults and reproductive were quantified in $79 \%$ of the studies, and larvae, settlers and early postsettlement mortality in just 52\%, $42 \%$ and 37\%, respectively (Table 5; Fig. 5). Decoupling occurred during nine $(47 \%)$ of the studies, and three causes of decoupling were identified in one of the studies. Temperature disrupting reproduction was the likely cause in $45 \%$ of the cases of decoupling, larval advection and poor food quality for larvae in the plankton in $27 \%$ and $9 \%$, and habitat selection during settlement in $18 \%$ (Table 5).

For molluscs overall, coupling was detected in $53 \%$ of 15 studies and $67 \%$ of 12 species from 12 papers (Table 5). Of the mussels, coupling was detected in $80 \%$ of five studies and species (PLD 12-35 days) from four papers. Weekly or twice weekly sampling of spawning, larvae, postlarvae and settlers of the mussel, Mytilus edulis, for 2 years demonstrated that all four stages of the early life history (reproductive output, larvae, settlement and recruitment) were coupled in a restricted lagoon $\left(3 \mathrm{~km}^{2}\right)$ in the Gulf of St. Lawrence, Canada, where the production and recruitment of different cohorts of mussel larvae were easily tracked (Toupoint et al. 2012). Two spawning events occurred at the beginning of the reproductive season during both years followed by two or three peaks of larvae, three peaks of postlarvae (pediveligers) occurring 21 days later during the first year and 11 days later during the second year, and settlement occurring 19-21 days thereafter. The abundances of larvae, postlarvae and settlers were similar both years, but recruitment was lower and 10 days later during the first year when essential fatty acids in phytoplankton were much lower. Smith et al. (2009) surveyed 


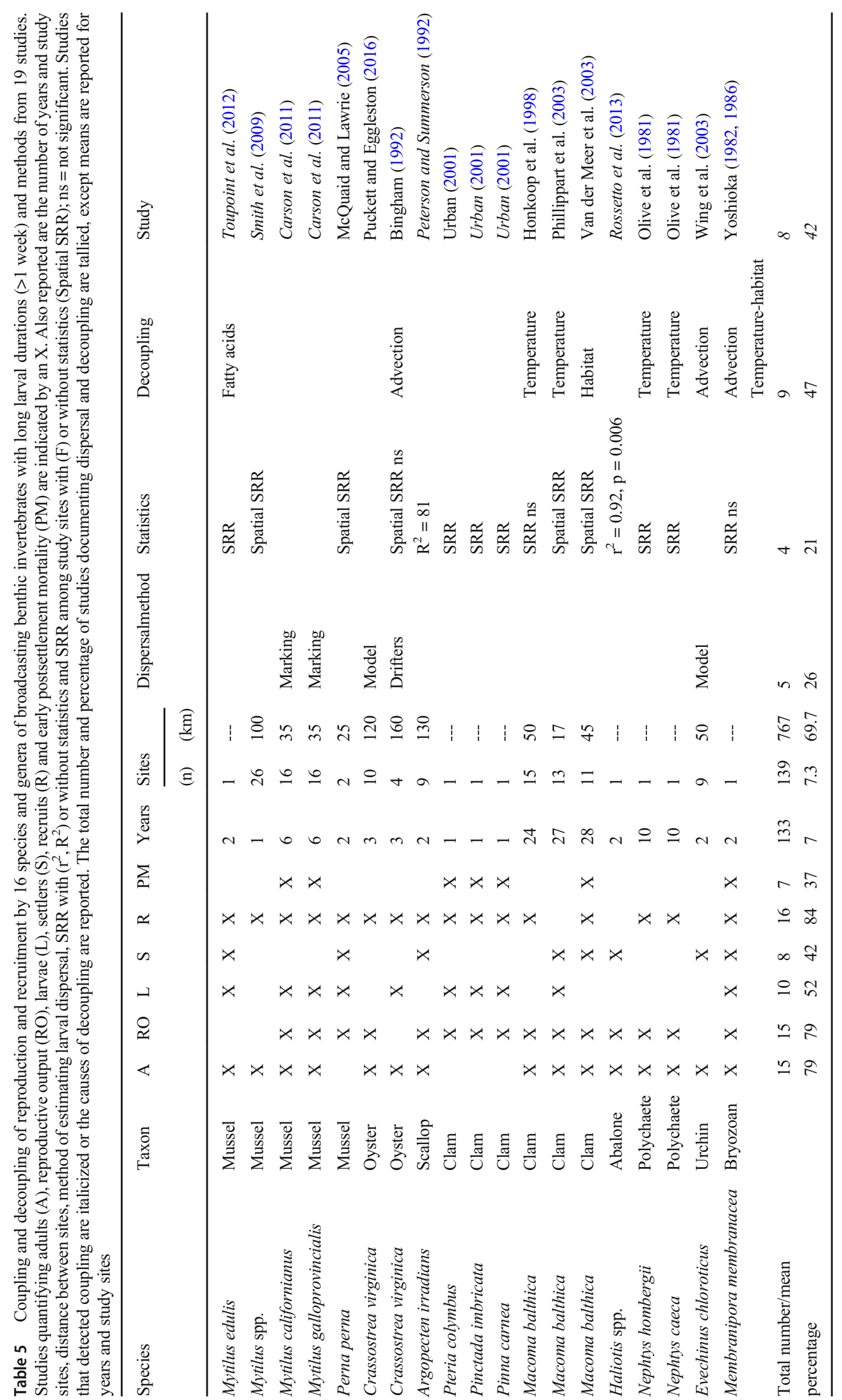


populations and recruitment of mussels, Mytilus spp., at 26 sites with distances between sites ranging from 1 to $100 \mathrm{~km}$ along the southern shore of the St. Lawrence Estuary, Canada, using a mixed nested-random sampling design. Crosscovariance detected coupling between adults and recruits between sites separated by $12-18 \mathrm{~km}(\mathrm{p}=0.018)$ and $24-30 \mathrm{~km}$ $(p=0.026)$ downstream but not for sites nearby or farther apart or within sites.

Carson et al. (2011) determined the persistence of metapopulations of two species of mussels that inhabit the open coast, Mytilus californianus, or bays, Mytilus galloprovincialis, in southern CA, USA. They used seasonal, size-structured metapopulation matrix models in which fecundity, growth and mortality rates were estimated from field surveys at representative sites and literature estimates of juvenile mortality, combined with time series of realized connectivities derived from trace-elemental fingerprinting of larval shells during peak reproduction in spring and fall for 6 years. Metapopulation growth of both species was most sensitive to changes in adult fecundity, survival and growth of juveniles, and population connectivity, in order of importance, but it was relatively insensitive to adult growth or survival. The highest metapopulation growth of both species occurred in years when more recruits were retained within source populations, but source-sink dynamics were nearly opposite for the two species due to seasonal differences in peak reproduction. Peak reproduction of M. galloprovincialis occurred in the spring when larvae were transported southward from the source population in the north, but self-recruitment was the dominant mechanism for persistence of this bay-dwelling species. The north received $72 \%$ of its recruits from local retention, $21 \%$ from in-season exchange against the flow and only $7 \%$ from exchange during the off season. Peak reproduction of M. californianus occurred in the fall when larvae were transported northward; the upstream southern population received $60 \%$ of its recruits from local retention, $29 \%$ from inseason exchange against the flow and $11 \%$ from northern imports during the off season.

McQuaid and Lawrie (2005) did not detect coupling among spawning, larval density and recruitment of the mussel, Perna perna, by sampling monthly for 14 months using a hierarchical sampling design along the southern coast of South Africa. Two sites were located $25 \mathrm{~km}$ apart, and three intertidal areas paired with nearshore stations $(600 \mathrm{~m}$ from shore) were located $500 \mathrm{~m}$ apart at each site. Larval and juvenile density were progressively less synchronous than spawning in time and space suggesting that spatial variation in planktonic processes affected larval supply and recruitment.

For clams, coupling between reproduction and recruitment was detected for $33 \%$ of six studies and $50 \%$ of four species (PLD 2-3 weeks) from four papers (Table 5). Urban (2001) investigated cyclic reproduction and temporal coupling of gonad production and larval and spat (new recruits) abundance monthly for three Caribbean species of clams from 1994 to 1998. Cycles of gonad production and spat abundance were closely correlated, but larval and spat abundance were not correlated for both Pinctada imbricata and Pinna carnea. Reproduction and spat abundance of Pteria colymbus were not coupled because there were both fewer peaks of spat and fewer spat than for the other two species. The El Niño of 1997-1998 did not affect the abundance of larvae and spat.

Decoupling of reproduction and recruitment occurred in time or space for the commercial clam, Macoma balthica (PLD 2-5 weeks) in three studies (Table 5). Honkoop et al. (1998) determined that the numbers of adults and the total number of eggs spawned per year were poor predictors of the abundance of recruits at the $50-\mathrm{km}^{2}$ tidal flat of Balgzand in the southwestern part of the Dutch Wadden Sea over 24 years. Fecundity explained only $7 \%$ of the interannual variation in recruitment, whereas interannual variation in water temperatures during the winter reproductive season explained $37 \%$ of the variation in spat. Fecundity and recruitment were both low after mild winters while adult densities generally were high. Survival of eggs to recruits in these years was always low, which may have been due to predation by juvenile brown shrimp, C. crangon, and juvenile green crabs, Carcinus maenas, which are important predators of early spat and abundant after mild winters.

Philippart et al. (2003) determined that rising seawater temperatures from climate change advanced the timing of spring spawning and decreased reproductive output and recruitment of $M$. balthica in the western Wadden Sea, Netherlands, over 29 years. Observed density-dependent mortality of juveniles appeared to be due to a mismatch between the timing of spawning and the phytoplankton bloom during spring and settlement of predatory juvenile shrimps on tidal flats during summer. In a related study conducted on M. balthica across the intertidal zone of sandflats at 11 sites in the same area over 29 years, individual lifetime egg production, based on longevity, growth and fecundity of 24 cohorts at the best sites in the lower intertidal zone and the poorest sites in the high intertidal zone differed by a factor of 10 (Van der Meer et al. 2003). Even though the high intertidal zone was poor habitat for adults, which experienced low growth, high mortality and low reproductive output, the density of recruits was highest in this harsh environment. Although many recruits moved to the lower intertidal zone during their first winter, most of them did not due to the risk of dying during migration or dispersing to worse deep habitat.

Puckett and Eggleston (2016) did not detect coupling between stock and recruitment of the oyster, $C$. virginica (PLD 2-3 weeks), in a network of 10 marine reserves in Pamlico Sound, NC, USA, by integrating demographic rates and connectivity estimates from a biophysical model within a metapopulation model. They tracked 2686 oysters to estimate demographic transitions, 2067 more oysters to estimate per- 
capita fecundity, settlement and postsettlement growth and mortality biweekly for three reproductive seasons in six of the 10 reserves. The network was not a self-persistent metapopulation, despite high demographic rates, due to limited local retention and connectivity of reserves. However, local retention generally was equivalent to or greater than connectivity, which strengthened coupling between reproduction and recruitment in each reserve, so source-sink and metapopulation dynamics primarily were driven by demographics related to larval production and subsequent survival of juveniles and adults. Apparent decoupling of stock and recruitment may have arisen from simplifying assumptions of the metapopulation model, including omitting known ontogenetic vertical migrations that can reduce dispersal and larvae arriving from outside the network where reproductive output may have been $500 \%$ greater. Coupling also was not apparent for C. virginica on prop roots of mangroves due to larval advection, as evidenced by similar recruitment $(\mathrm{F}=2.04, \mathrm{p}=0.121)$ in four neighboring channels (Bingham 1992).

Peterson and Summerson (1992) found that spawning adults explained $81 \%$ of the variation in settlers and $80 \%$ of the variation in new recruits across nine grounds of sedentary bay scallops, Argopecten irradians concentricus (PLD 35-45 days), in NC, USA, during the first year of the study. Patterns of adult and recruit abundance were broadly coherent at a basin scale across three water bodies. In the second year of the study, spawning adults explained over $65 \%$ of the variation in new recruits, although the relationship to settlers was not significant due to anomalously high settlement at two of the sites.

Rossetto et al. (2013) detected coupling between reproductive output and settlement of pink abalone, Haliotis fulgens, and green abalone, Haliotis corrugate (PLD 3 weeks). Settlement on collectors placed inside and outside two marine reserves at Isla Natividad, Baja California Sur, Mexico, was monitored biweekly throughout the 4-month spawning season, the abundance and size structure of abalone were surveyed yearly by divers during two consecutive years and the number of eggs produced by the population was estimated by modeling sexual maturity relative to body size. Reproductive output and settlement were weakly correlated $\left(r^{2}=0.58, p=\right.$ 0.12 ), and the relationship was stronger when sites were combined $\left(r^{2}=0.92, p=0.006\right)$, suggesting that greater egg production by large, fecund individuals inside reserves resulted in greater settlement. The slope of the linear relationship indicated that $0.2-0.3 \%$ of eggs released in the water column were fertilized and metamorphosed to postlarvae.

Interannual variation in temperature switched the relative dominance of two congeneric polychaetes on a beach in the River Tyne estuary, England, because temperatures favoring reproductive success for one species were unfavorable for the other species (Olive et al. 1981). Extremely cold temperatures during 1979 and 1980 caused reproductive failure of Nephtys hombergii, which resorbed their gametes rather than spawning, so these year classes were nearly absent from the population unlike 1970-1975 when temperatures were normal. Conversely, $N$. caeca was consistently abundant during 1976-1980 but scarce in 1973 and 1975.

Coupling of reproduction and recruitment of the sedentary sea urchin, Evechinus chloroticus (PLD 4-6 weeks), in Doubtful-Thompson Sound fjord, New Zealand, was not apparent for individual populations but may have occurred for the metapopulation (Wing et al. 2003). The metapopulation was highly structured with large, consistent differences in abundance, growth, gamete production and larval settlement at nine sites over 2 years. The highest growth rates and gamete production occurred at the entrances to the fjord, and the highest abundance, aggregation and settlement rates occurred from entrance to mid-fjord sites. A hydrodynamic model indicated that populations at the entrances to the fjord were reproductive sources and those well within the fjord were sinks with a single cohort of larvae being retained in the fjord.

Coupling of reproduction, larval abundance and recruitment was not detected for the encrusting, colonial bryozoan, Membranipora membranacea, inhabiting kelp, M. pyrifera, canopies at eight sites in southern CA, USA, for 2 years (Yoshioka 1982, 1986). The stock-recruitment relationship was highly variable $\left(r^{2}=16 \%\right)$, but the recruitment-stock relationship was far more variable $\left(r^{2}=0.03 \%\right)$, indicating that benthic processes were even more chaotic than planktonic processes during the 4-week PLD (Fig. 7). Variability in recruitment decreased considerably by investigating intervening life stages and environmental factors. Stock-larval abundance and larval abundance-recruitment relationships explained $44 \%$ and $69 \%$ of the variability, respectively. Predation by nudibranchs, larval advection during upwelling and warm surface water reducing settlement in the kelp canopy accounted explained $64 \%$ of the variability in recruitment. After settlement, populations varied by more than an order of magnitude between consecutive biweekly sampling intervals and over a thousand-fold after 6 weeks primarily due to predation, which is largely responsible for the short lifespan ( $\sim 6$ weeks) of colonies. Variability in stock, reflecting variations in benthic factors responsible for the growth and survival of colonies, also was reduced by considering intervening life stages but less than for planktonic processes affecting recruitment. Densities of zooids (individuals) in newly recruited colonies were highly correlated with the abundance of colonies 2 weeks later $\left(r^{2}=94 \%\right)$. Mortality was negligible on newly recruited colonies because predatory nudibranchs and fishes did not prey on colonies in low densities. Recruitment still accounted for considerable $\left(\mathrm{r}^{2}=68 \%\right)$ variability in zooid densities 2 weeks later, but the relationship between recruitment and zooid densities disappeared completely 4 weeks after settlement $\left(r^{2}=0.03 \%\right)$; the variability between recruitment and stock increased rapidly over time. A 12 -fold density- 


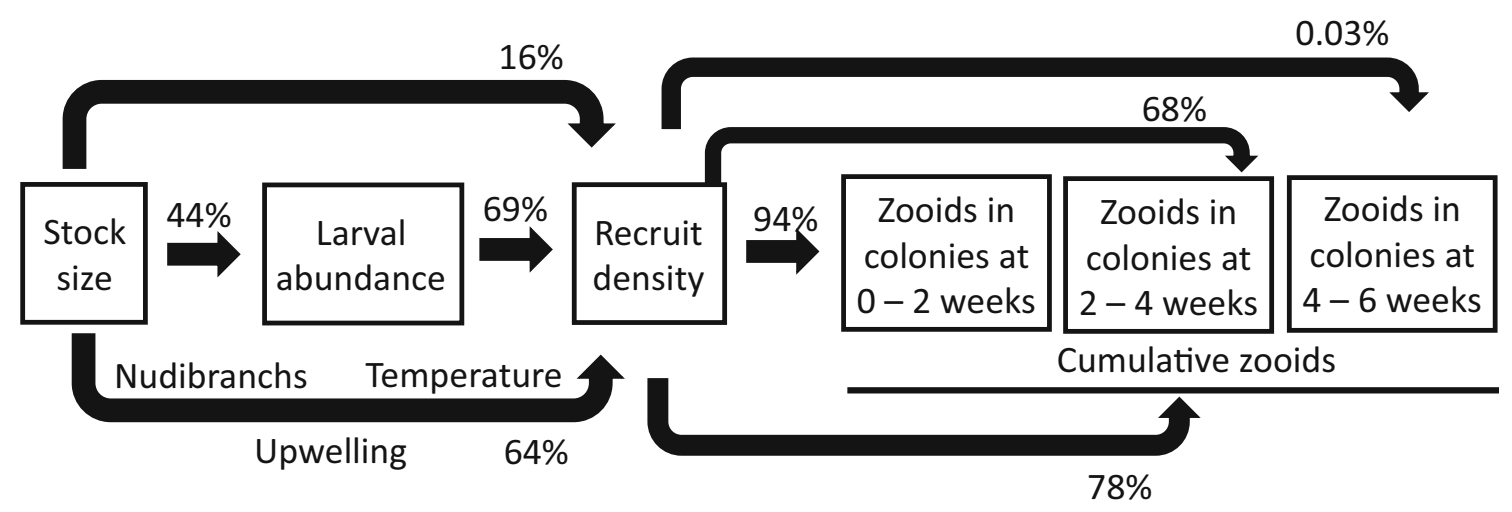

Fig. 7 Percent variability accounted for by regression analyses of intervening stages in stock-recruitment relationships of the bryozoan, Membranipora membranacea, on the coast of southern CA, USA. Stock-recruitment relationships were highly variable $\left(\mathrm{r}^{2}=16 \%\right)$, but recruitment-stock relationships were even more variable $\left(r^{2}=0.03 \%\right)$, suggesting that benthic processes are more variable than are planktonic processes. Variability in these relationships was reduced considerably

dependent effect on reproduction from space limitation and predation over the 1000-fold range in recruitment resulting from density-independent factors explained $7 \%$ of the variation regulating populations and ensuring their persistence.

\section{Discussion}

Coupling between reproductive output and recruitment was common in a wide diversity of benthic invertebrates, fishes, seagrasses and kelp in contrast to the prevailing view. Overall, coupling occurred in $62 \%$ of 112 studies and $64 \%$ of 81 species from 80 papers (Fig. 3A). Coupling was often found because it is easier to detect in benthic than pelagic species. Population size, reproductive output and recruitment can be more reliably quantified for benthic than pelagic species, because they commonly are sessile or sedentary and are confined to discrete habitats as adults. Reproduction only occurs in these discrete habitats and propagules must recruit there to survive.

The degree of coupling was determined by a statistical SRR in only $38 \%$ of studies. By including studies that found clear evidence of coupling or decoupling without calculating a statistical SRR, 34\% more studies contributed to the review, which together comprised $72 \%$ of the evidence used to evaluate the frequency of coupling. In addition, a spatial SRR (determined across more than one site across the study area) both with and without statistics contributed $12 \%$ and $6 \%$ more studies to the review. Complementary approaches used to detect coupling in studies included models $(5 \%)$, visually tracking mortality and dispersal of ascidian larvae (4\%), parentage analysis of reef fishes $(4 \%)$ and natural elemental markers of mussels (2\%). Incorporating diverse approaches provided when intervening life stages and environmental factors were considered: stock-larval abundance and larval abundance-recruitment relationships explained $44 \%$ and $69 \%$ of the variability. In the latter case, nudibranch predation, upwelling and temperature together with stock size explained $64 \%$ of the variability in recruitment. Thus, variability in recruitment can be explained by a few causal mechanisms (after Yoshioka (1986))

more evidence and a more comprehensive evaluation of the frequency of coupling.

The degree of coupling differed considerably among life histories of animals. Coupling depended on both reproductive mode and PLD. Reproductive mode had a pronounced effect on coupling. For brooders, coupling occurred in $72 \%$ of 61 studies and $74 \%$ of 42 species, but for broadcasters, it occurred in just $46 \%$ of 35 studies and $53 \%$ of 30 species (Fig. $3 \mathrm{~A})$. Coupling was much greater for brooders than broadcasters, likely because relatively large, strongly swimming larvae begin regulating dispersal as soon as they hatch, omitting the obligatory period of passive dispersal from natal populations by broadcasters. The effect of PLD on coupling was not quite as pronounced as reproductive mode, but coupling was still considerably stronger in taxa with short than long PLDs. For short PLDs, coupling occurred in $74 \%$ of 34 studies and $76 \%$ of 29 species, but for long PLDs, it occurred in $56 \%$ of 62 studies and $58 \%$ of 43 species (Fig. 3A). Consequently, the highest degree of coupling occurred for brooders with brief PLDs, occurring in 94\% of 18 studies and $93 \%$ of 15 species, and the lowest degree of coupling occurred for broadcasters with long PLDs, occurring in $42 \%$ of 19 studies and $50 \%$ of 16 species (Fig. 8). Furthermore, coupling was stronger for brooders with long PLDs, occurring in $63 \%$ of 43 studies and $61 \%$ of 27 species, than broadcasters with short PLDs, occurring in 50\% of 16 studies and $57 \%$ of 14 species (Fig. 8). These results are consistent with longstanding hypotheses that invertebrates and fishes with short PLDs are less likely to be advected far from natal populations to unsuitable settlement sites or die in the plankton from predation, food limitation in quantity or quality or physiological stress than taxa than taxa with long PLDs (Hjort 1914; Thorson 1950; Morgan 1995; Marshall and Morgan 2011; 


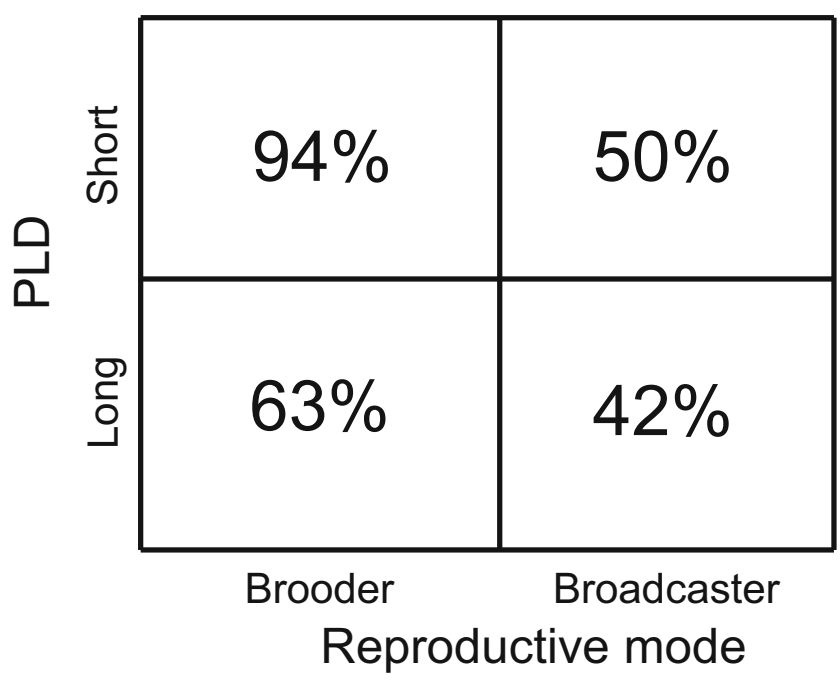

Fig. 8 Summary diagram of the frequency of coupling between reproductive output and larval recruitment by brooding and broadcastspawning benthic animals with short $(<1$ week) and long ( $>1$ week) planktonic larval durations (PLD) from 96 studies. The frequency of coupling in benthic seagrasses and kelp, which release passive seeds or spores with short planktonic durations, occurred in $56 \%$ of 16 studies

Hare 2014; Pepin 2016). Visually tracking ascidian larvae revealed that larvae settled within meters of where they were released while predation was the main cause of mortality. Decoupling occurred 33 times during the 96 studies on benthic animals (34\%), occurring primarily in the plankton (48.5\%) due to advection (33\%) and food limitation (15\%) and during reproduction due thermal stress $(45.5 \%)$, whereas it occurred infrequently after settlement due to poor habitat selection by settlers $(6 \%)$.

Coupling was similar in seagrasses, kelp and animals overall. It occurred in $56 \%$ of 16 studies and nine species in seagrasses and kelp and $63 \%$ of 96 studies and $65 \%$ of 72 species in animals (Fig. 3A). Coupling between reproductive output and settlement in seagrasses may be common because seeds usually are in the water column briefly and disperse from just several to tens of meters due to negative buoyancy and barbs or bristles for attachment (Blanchette et al. 1999; Ruiz-Montoya et al. 2012), although dispersal of seeds and germinated seeds can occur after seeds initially settle to the substrate by resuspension from waves and currents. However, coupling was much greater for animals with life histories most like seagrasses and kelp, brooders with short PLDs, occurring in $94 \%$ of 18 studies and $93 \%$ of 15 species. For these animals, swimming behavior of larvae that are competent to settle soon after they are released may limit advection from the study site more than passively dispersed seeds.

Although fisheries biologists have long determined larval mortality by calculating stock-recruitment relationships, benthic ecologists can determine it more precisely by quantifying reproductive output and settlement. Coupling was detected in $79 \%$ of studies that quantified both reproductive output and settlement, whereas it was just $60 \%$ for studies that quantified both adults and recruitment. However, both reproductive output and settlement were quantified in only $29 \%$ of studies, whereas both adults and recruitment were quantified in $71 \%$ of the 96 studies, presumably because it is more difficult to measure reproductive output than adults and settlement than recruitment. Settlement should be monitored at least daily before much postsettlement mortality occurs, whereas recruitment is monitored at longer sampling intervals. Of the studies that quantified both reproductive output and settlement, $75 \%$ investigated brooders presumably because it is easier to measure reproductive output for brooders than broadcasters. Although both reproductive output and recruitment were quantified for all seagrass studies, settlement was determined in only one study (Reed et al. 2009).

Sedentary benthic species inhabiting discrete habitats also lend themselves to experimental designs that are more likely to detect coupling between reproductive output and settlement than for many vagile, wide-ranging fisheries species. Studies that encompassed metapopulations spanning long distances were more likely to detect coupling than studies that focused on one site, because larvae may disperse from the focal population and will not be taken into account. However, it depended on life histories. Overall, there was little difference; coupling was detected in $57 \%$ of 49 ecological studies that surveyed more than one site, averaging 12 sites spanning 250 $\mathrm{km}$, and it was similar (55\%) in the 42 studies that surveyed just one site. However, detecting coupling by sampling one site was far more likely for brooders than broadcasters; it was $100 \%$ in 16 studies conducted at one site for brooders and only $25 \%$ in 16 studies for broadcasters. Brooders release swimming larvae that are able to remain at the study site, whereas broadcasters release passively drifting eggs and sperm that are far more likely to be advected beyond it. The PLD mattered little in detecting coupling at a single site; it was $60 \%$ in 20 studies conducted at one site for species with short PLDs and $67 \%$ in 12 studies conducted at one site for species with long PLDs. Sampling more than one site was more important for detecting coupling by species with long than short PLDs because the probability of advection increases the longer larvae remain in the plankton regardless of whether they release eggs or larvae. At more than one site, coupling was $93 \%$ in 14 studies for species with short PLDs, whereas it was just 38\% in 29 studies for species with long PLDs. Whether species released eggs or larvae only mattered a little in detecting coupling at more than one site, because larvae are captured regardless of whether they are advected from the site or not. Coupling at more than one study site was detected in $50 \%$ of 24 studies for brooders and $63 \%$ of 19 studies for broadcasters. Like most animals, coupling was more readily detected in seagrasses and kelp by surveying multiple sites. Coupling was detected in only $33 \%$ of 10 studies on seagrasses that surveyed just one site, but it was $60 \%$ in five 
studies that surveyed an average of six sites spanning $58 \mathrm{~km}$. It also was detected in the only study on kelp spanning $900 \mathrm{~km}$.

The ability to detect coupling improved by accounting for propagules advected from study sites. Dispersal was estimated in only $21 \%$ of the 112 studies, but coupling was detected in $83 \%$ of them. Coupling was detected in $100 \%$ of 11 studies that incorporated dispersal for species with short PLDs and $83 \%$ of the six studies for brooders with long PLDs, but it was detected in only $40 \%$ of the five studies for broadcasters with long PLDs. Detecting coupling for this type of life history likely is most challenging, because eggs passively disperse and larvae spend a long time developing in the plankton increasing advection from parents. Hence, it is especially important to incorporate dispersal to detect coupling for these species. Estimating dispersal takes considerable effort (Thorrold et al. 2002) and is usually investigated separately from detailed demographic studies on stock-recruitment relationships. However, incorporating dispersal would increase the ability to detect coupling in future studies. Five approaches effectively estimated dispersal trajectories, including visual tracking of ascidian larvae in five studies, parentage analysis of reef fish larvae in four studies, natural elemental marking of mussel larvae in two studies, modeling in six studies and drifters in 10 studies from one paper.

The extent of coupling was detected by incorporating a hierarchical sampling design, but only six studies did so, determining it in $83 \%$ of the studies and species. Coupling was detected for multiple sites that were spaced far apart but not for smaller spatial scales in five studies (Hughes et al. 2000, 2019; Smith et al. 2009; Hidas et al. 2013; Rognstad et al. 2014). Coupling was not detected in the sixth study consisting of just two sites that were spaced closer together at the largest scale (25 km; McQuaid and Lawrie 2005). These hierarchical studies indicated that coupling between reproductive output and recruitment can occur as little as $12-28 \mathrm{~km}$ or $30-100 \mathrm{~km}$ apart and as much as 250-400 km apart. Both the smallest and largest scales of coupling were by broadcast-spawners; however, the smallest scale occurred in an estuary (Smith et al. 2009) rather than the open coast where larval dispersal is less confined and coupling is more difficult to detect. Incorporating a hierarchical sampling design into studies eventually will reveal the effect of reproductive mode and location on the spatial extent of coupling.

Temporal coupling between reproductive output and settlement was established by correlating spawning or hatching with peak settlement. Although $65 \%$ of studies were conducted for as long as just 3 years, coupling was still detected by $58 \%$ of them. Coupling was detected better by longer studies (67\%), although this difference is partially attributable to life histories. Studies on species with short PLDs were largely conducted for 3 years or less (90\% of 50 studies), and coupling was detected far more often for these species (94\% of 18 studies on brooders, $94 \%$ of 16 studies on broadcasters and
$81 \%$ of 16 studies on seagrasses and kelp) than for those with long PLDs in studies conducted for 3 years or less ( $47 \%$ of 43 studies on brooders and $63 \%$ of 19 studies on broadcasters). Thus, coupling can be readily detected by conducting short studies, but the probability of detecting it improves by conducting lengthier studies for species with long PLDs.

Quantifying successive stages in life cycles while monitoring environmental conditions revealed the stage that reproductive failure occurred and likely causes of decoupling. Predictably, adult abundance, reproductive output and recruitment were collected much more often $(76 \%, 69 \%$ and $78 \%$ of 96 studies, respectively) than larval abundance, settlement and early postsettlement mortality (39\%, 47\% and 42\%; Fig. 5). Decoupling was detected 33 times in invertebrates and fishes. It primarily occurred in the plankton $(48.5 \%)$ due to advection or behaviorally mediated dispersal from study sites (33\%) and food limitation (15\%) and during reproduction (45.5\%) due to thermal stress and much less often during settlement due to poor habitat selection (6\%; Fig. 3B). Although fertilization is a critical stage in the life cycle, it was not investigated for invertebrates and fishes unlike seagrasses and kelp. In seagrasses, shoots, flowers, seed production and seedling recruitment were collected in $100 \%$ of 15 studies, and fertilization, the seed bank and seed germination were investigated far less often $(20 \%, 53 \%$ and $53 \%$ of the studies, respectively; Fig. 4). Decoupling occurred more often in seagrasses $(60 \%$ of nine cases) than animals (34\% of 33 cases; Fig. 3B). Like animals, it frequently occurred during reproduction $(44.4 \%)$, but it was greater after settlement $(33.3 \%)$ than in the plankton (22.2\%) for seagrasses (Fig 3B). Postsettlement decoupling in seagrasses was due to mortality of seedlings from self-shading and failure of seeds to germinate $(75 \%$ and $25 \%$ of four studies). Decoupling during reproduction ( $44 \%$ of cases) was due to physiological stress during seed production and pollen limitation ( $75 \%$ and $25 \%$ of four cases) and was greater than decoupling in the plankton from the advection of seeds in two cases $(22 \%)$. Lower decoupling in the plankton likely occurred due to less advection of heavier seeds and no mortality from food limitation. Low decoupling by early postsettlement mortality in animals could have arisen because it was not a focus of studies that primarily were concerned with determining coupling between reproductive output and settlement.

\section{Conclusion and Future Directions}

Conclusions regarding coupling between reproductive output and settlement should be evaluated carefully because they have profound implications for dynamics of populations and communities and evolution of life histories. Stochastic variation in planktonic processes do not necessarily obliterate the relationship between the production of propagules and the 
number of settlers. Indeed, adaptation to planktonic mortality could not have arisen if survival through the planktonic phase occurred by chance, rather, inheritance of traits by natural selection only occurs if the benthic and planktonic phases of the life cycle are coupled (Morgan 1995; Marshall and Morgan 2011). Positive and negative feedback between stages of the life cycle must occur for complex life histories to evolve by natural selection. Differential survival of offspring in the plankton must result in greater reproductive success of adults for reproductive timing, behavioral regulation of larval transport, larval defenses and settlement preferences to evolve.

The perceived lack of coupling is due more to the approaches used to detect coupling between reproductive output and settlement rather than so-called stochastic planktonic processes themselves. The ability to detect coupling depends on the spatial and temporal scales of the study. Coupling is unlikely to be detected locally because larvae disperse beyond the study area while larvae from elsewhere recruit there, especially for species with long PLDs. However, coupling likely will be detected at a scale that matches the distance larvae disperse because large variations in reproductive output will be reflected in the number of settlers across the area. Quantifying larval dispersal by hierarchical sampling, visual tracking, genetic markers, geochemical signatures, biophysical numerical models and other techniques (Thorrold et al. 2002) establish the extent of coupling for studies conducted at smaller scales. The frequency of coupling and causes of decoupling are revealed by conducting studies over multiple reproductive seasons while monitoring environmental factors. Thus, coupling between reproductive output and settlement and the causes of decoupling can readily be detected by well-designed studies. Furthermore, comparing multiple species with different reproductive modes and PLDs at the same time will best elucidate the consequences of these life history traits on coupling between reproductive output and recruitment and the dynamics of populations communities (Bingham 1992). More commonly, concurrently comparing multiple species with similar reproductive modes and PLDs reveals the consequences of different early life history traits on coupling between reproductive output and recruitment on population and community dynamics (Olive et al. 1981; Uriz et al. 1998; Urban 2001), which can reinforce the occurrence of coupling (Hughes et al. 2000, 2019; Carson et al. 2011), decoupling (Nozawa et al. 2006) or appearance of decoupling (Robertson et al. 1993) depending on the approach.

Fully understanding and predicting changes in the spatial and temporal distribution and abundance as well as the population structure and growth rate require a complete model of population dynamics to determine how multiple processes affect individuals during both phases of the life cycle. Obtaining data for the benthic phase of the life cycle is relatively straightforward, so the key is obtaining reliable information for the planktonic phase of the life cycle. Eckman (1996) proposed either developing a stage-based, population matrix model or a model that specifies discrete stages of the population in terms of simultaneous differential equations that may be solved in both time and space. He argued that all of the key terms of the models could be predicted or estimated empirically at appropriate spatial and temporal scales, acknowledging that it would be challenging. My review showed that "closing the larval loop" has now been accomplished many times for diverse benthic organism in well-designed ecological studies as well as for some commercial species using fisheries data, thereby paving the way for more population dynamics models. Some of the ecological studies that detected coupling have been conducted by a single doctoral student (Olson 1985; Davis 1988, 1989; Stoner 1990; Bingham 1992; Hurlbut 1992; Hameed et al. 2016; Satterthwaite 2019) or investigator (Barnes 1956; Gotelli 1987; Urban 2001; Shelton 2008) with limited funding. Therefore, thorough, well-funded studies determining coupling between reproductive output and settlement at appropriate spatial and temporal scales may routinely detect coupling in benthic species.

Pineda et al. (2009) suggested that the task could be simplified by reducing the set of empirically derived processes and rates to larval upward swimming, onshore transport, mortality and recruitment to the adult population. However, determining the multiple processes delivering larvae to shore (Shanks 1995; Morgan et al. 2009, 2017; Fernández Aldecoa et al. 2019) and reliably estimating larval mortality in an advective environment (Morgan 1995; White et al. 2014) are challenging tasks themselves, and this approach limits processes regulating population dynamics to the larval recruitment stage of the life cycle.

Coupling between reproductive output and settlement and the causes of decoupling can be readily detected for benthic species, so the poor stock-recruitment relationships typical of vagile, wide-ranging pelagic species may be due more to the difficulty of detecting them than actual decoupling. Benthic ecologists should advance our understanding of population and community dynamics by moving beyond simply using larval recruitment as a proxy for the planktonic phase of the life cycle. A concerted effort is needed to concurrently determine how environmental factors affecting reproductive output and the survival, transport and settlement of larvae regulate populations and communities. Environmental conditions influencing these processes will determine whether individuals live or die, populations persist, expand or contract, and communities change or maintain their species composition and structure. Broadening our understanding of how environmental factors operate at each juncture of the life cycle is needed to better inform the management of fisheries as one or more than one stock, design and evaluation of networks of marine protected areas and mitigation of the impacts of a 
changing climate on the distribution and abundance of populations and composition and structure of communities. The realization that larval retention is much more common than was widely believed means that the high proportion of larvae returning to natal populations strengthens links between stock and recruitment, increases vulnerability to recruitment overfishing and modifications of local habitats, enhances benefits from local marine protected areas and increases the potential for local adaptation of populations (Strathmann et al. 2002; Burgess et al. 2016). Of course, larval dispersal is just one factor affecting coupling between reproductive output and recruitment - larval mortality is also a key factor. By considering both larval mortality and dispersal, my review demonstrates that coupling as a whole is common, which reinforces the conclusions drawn regarding the implications of larval retention being common. Climate change will affect both larval dispersal and mortality, but the effect on coupling of reproductive output and larval recruitment likely will depend on life histories, with planktotrophs, calcifiers, poor swimmers and habitat specialists being most affected (Bashevkin et al. 2020).

\section{Acknowledgements Comments by Erin Satterthwaite and Helen Killeen improved the manuscript.}

Funding This research was funded by California Sea Grant (R/FISH2018) and is a contribution of the Bodega Marine Laboratory.

Open Access This article is licensed under a Creative Commons Attribution 4.0 International License, which permits use, sharing, adaptation, distribution and reproduction in any medium or format, as long as you give appropriate credit to the original author(s) and the source, provide a link to the Creative Commons licence, and indicate if changes were made. The images or other third party material in this article are included in the article's Creative Commons licence, unless indicated otherwise in a credit line to the material. If material is not included in the article's Creative Commons licence and your intended use is not permitted by statutory regulation or exceeds the permitted use, you will need to obtain permission directly from the copyright holder. To view a copy of this licence, visit http://creativecommons.org/licenses/by/4.0/.

\section{References}

Abdul Wahab, M.A., R. de Nys, N. Webster, and S. Whalan. 2014. Larval behaviours and their contribution to the distribution of the intertidal coral reef sponge Carteriospongia foliascens. PLoS One 9 (5): e98181.

Barbosa, A.C.C., C.C. Gomes, G.C. Pereira, M. Bueno, and A.A.V. Flores. 2016. Local biological drivers, not remote forcing, predict settlement rate to a subtropical barnacle population. Marine Ecology Progress Series 543: 201-208.

Barnes, H. 1956. Balanus balanoides (L.) in the Firth of Clyde: the development and annual variation of the larval population, and the causative factors. Journal of Animal Ecology 25 (1): 72-84.

Bashevkin, S., C. Dibble, R. Dunn, J. Hollarsmith, G. Ng, E. Satterthwaite, and S. Morgan. 2020. Larval dispersal in a changing ocean with an emphasis on upwelling regions. Ecosphere 11 (1): e03015. https://doi.org/10.1002/ecs2.3015.

Beldade, R., S.J. Holbrook, R.J. Schmitt, S. Planes, D. Malone, and G. Bernardi. 2012. Larger female fish contribute disproportionately more to self-replenishment. Proceedings of the Royal Society of London B 279: 2116-2121. https://doi.org/10.1098/rspb.2011.2433

Bingham, B.L. 1992. Life histories in an epifaunal community: coupling of adult and larval processes. Ecology 73 (6): 2244-2259.

Blanchette, C.A., S.E. Worcester, D.C. Reed, and S.J. Holbrook. 1999. Algal morphology, flow, and spatially variable recruitment of surfgrass Phyllospadix torreyi. Marine Ecology Progress Series 184: 119-128.

Boddeke, R. 1989. Management of the brown shrimp (Crangon crangon) stock in Dutch coastal waters. In Marine invertebrate fisheries: their assessment and management, ed. J.F. Caddy, 35-62. New York: Wiley.

Boddeke, R., and H.B. Becker. 1979. A quantitative study of the fluctuations of the stock of brown shrimp (Crangon crangon) along the coast of the Netherlands. Rapports et Procès-verbaux des réunions Conseil International pour L'exploration de la Mer 172: 239.

Brosset, P., H. Bourdages, M. Blais, M. Scarratt, S. Plourde, and E. Anderson. 2019. Local environment affecting northern shrimp recruitment: a comparative study of Gulf of St. Lawrence stocks. ICES Journal of Marine Science 76 (4): 974-986.

Buckel, C.A., C.A. Blanchette, R.R. Warner, and S.D. Gaines. 2012. Where a male is hard to find: consequences of male rarity in the surfgrass Phyllospadix torreyi. Marine Ecology Progress Series 449: 121-132.

Burgess, S.C., K.J. Nickols, C.D. Griesemer, L.A.K. Barnett, A.G. Dedrick, E.V. Satterthwaite, L. Yamane, S.G. Morgan, J.W. White, and L.W. Botsford. 2014. Beyond larval connectivity: how empirical methods can quantify population persistence to improve marine protected area design. Ecological Applications 24 (2): $257-$ 270.

Burgess, S.C., M.L. Baskett, R.K. Grosberg, S.G. Morgan, and R.R. Strathmann. 2016. When is dispersal for dispersal? Unifying marine and terrestrial perspectives. Biological Reviews 91 (3): 867-882.

Cadrin, S.X., D.R. Goethel, M.R. Morse, G. Fay, and L.A. Kerr. 2019. "So, where do you come from?" The impact of assumed spatial population structure on estimates of recruitment. Fisheries Research 217: 156-168.

Caputi, N., B.C.F. Chub, and R.S. Brown. 1995. Relationship between spawning stock, environment, recruitment and fishing effort for the western rock lobster, Panulirus cygnus, fishery in Western Australia. Crustaceana 68: 213-226.

Caputi, N., J.W. Penn, L.M. Joll, and C.F. Chubb. 1998. Stockrecruitment-environment relationships for invertebrate species of Western Australia. In Proceedings of the North Pacific Symposium on Invertebrate Stock Assessment and Management, ed. G.S. Jamieson and A. Campbell, Canadian Special Publication of Fisheries and Aquatic Sciences 125, pp. 247- 255.

Carballo, J.L. 2000. Larval ecology of an ascidian tropical population in a Mediterranean enclosed ecosystem. Marine Ecology Progress Series 195: 159-167.

Carloni, J.T., R. Wahle, P. Geoghegan, and E. Bjorkstedt. 2018. Bridging the spawner-recruit disconnect: trends in American lobster recruitment linked to the pelagic food web. Bulletin of Marine Science 94 (3): 719-735.

Carson, H.S., G.S. Cook, P.C. Lopez-Duarte, and L.A. Levin. 2011. Evaluating the importance of demographic connectivity in a marine metapopulation. Ecology 92 (10): 1972-1984.

Castorani, M.C.N., D.C. Reed, P.T. Raimondi, F. Alberto, T.W. Bell, K.C. Cavanaugh, D.A. Siegel, and R.D. Simons. 2017. Fluctuations in population fecundity drive variation in demographic connectivity and metapopulation dynamics. Proceedings of the 
Royal Society of London B 284 (1847): 20162086. https://doi.org/ 10.1098/rspb.2016.2086.

Condie, S.A., N.R. Loneragan, and D.J. Die. 1999. Modelling the recruitment of tiger prawns Penaeus esculentus and P. semisulcatus to nursery grounds in the Gulf of Carpentaria, northern Australia: implications for assessing stock-recruitment relationships. Marine Ecology Progress Series 178: 55-68.

Crocos, P.J., and T.D. van der Velde. 1995. Seasonal, spatial and interannual variability in the reproductive dynamics of the grooved tiger prawn Penaeus semisulcatus in Albatross Bay, Gulf of Carpentaria, Australia: the concept of effective spawning. Marine Biology 122 (4): 557-570.

Cury, P.M., J.-M. Fromentin, S. Figuet, and S. Bonhommeau. 2014. Resolving Hjort's dilemma. Oceanography 27 (4): 42-47.

Cushing, D.H. 1990. Plankton production and year-class strength in fish populations - an update of the match/ mismatch hypothesis. Advances in Marine Biology 26 (249): 293.

Danilowicz, B.S. 1997. A potential mechanism for an episodic recruitment of a coral reef fish. Ecology 78 (5): 1415-1423.

Davis, A.R. 1988. Effects of variation in initial settlement on distribution and abundance of Podoclavella moluccensis. Journal of Experimental Marine Biology and Ecology 117 (2): 157-167.

Davis, A.R. 1989. Temperature correlates with the daily release of larvae and their settlement in a temperate Australian ascidian. In Reproduction, genetics and distributions of marine organisms, ed. J.S. Ryland, 61-65. Fredensborg: Olsen and Olsen.

Davis, A.R., and A.J. Butler. 1989. Direct observations of larval dispersal in the colonial ascidian Podoclavela moluccensis Sluiter: evidence for closed populations. Journal of Experimental Marine Biology and Ecology 127 (2): 189-203.

Deng, J., J. Zhu, and R. Ren. 1996. A study on dynamics of stock recruitment relationship of penaeid shrimp in the Pohai Sea. Journal of Fisheries Science China 3: 20-26.

Diaz-Almela, E., N. Marba, R. Martınez, R. Santiago, and C.M. Duarte. 2009. Seasonal dynamics of Posidonia oceanica in Magalluf Bay (Mallorca, Spain): temperature effects on seagrass mortality. Limnology and Oceanography 54 (6): 2170-2182.

Eckman, J.E. 1996. Closing the larval loop: linking larval ecology to the population dynamics of marine benthic invertebrates. Journal of Experimental Marine Biology and Ecology 200 (1-2): 207-237.

Ehrhardt, N.M., and M.D. Fitchett. 2010. Dependence of recruitment on parent stock of the spiny lobster, Panulirus argus, in Florida. Fisheries Oceanography 19 (6): 434-447.

Fernández Aldecoa, R.G., L.B. Ladah, S.G. Morgan, M.E. Solana Arellano, and A. Filonov. 2019. Delivery of zooplankton to the surf zone during strong internal tidal forcing and onshore winds in Baja California. Marine Ecology Progress Series 625: 15-26.

Giese, A.C., and H. Khanatani. 1987. Maturation and spawning. In Reproduction of marine invertebrates, ed. A.C. Giese, J.S. Pearse, and V.B. Pearse, vol. 9, 251-329. California: Blackwell Scientific.

Golbuu, Y., E. Wolanski, J.W. Idechong, S. Victor, A.L. Isechal, N.W. Oldiais, D. Idip Jr., R.H. Richmond, and R. van Woesik. 2012. Predicting coral recruitment in Palau's complex reef archipelago. PLoS One 7 (11): e50998.

Gotelli, N.J. 1987. Spatial and temporal patterns of reproduction, larval settlement, and recruitment of the compound ascidian Aplidium stellatum. Marine Biology 94 (1): 45-51.

Gracia, A. 1991. Spawning stock-recruitment relationships of white shrimp in the southwestern Gulf of Mexico. Transactions of the American Fisheries Society 120 (4): 519-527.

Gracia, A. 1996. White shrimp (Penaeus setiferus) recruitment overfishing. Marine and Freshwater Research 47 (1): 59-65.

Haltuch, M.A., E.N. Brooks, J. Brodziak, J.A. Devine, K.F. Johnsona, N. Klibansky, R.D.M. Nash, M.R. Payne, K.W. Shertzer, S. Subbey, and B.K. Wells. 2019. Unraveling the recruitment problem: a review of environmentally-informed forecasting and management strategy evaluation. Fisheries Research 217: 198-216.

Hameed, S.O., J.W. White, S.H. Miller, K.J. Nickols, and S.G. Morgan. 2016. Inverse approach to estimating larval dispersal reveals limited population connectivity along $700 \mathrm{~km}$ of wave-swept open coast. Proceedings of the Royal Society of London B 283: 20160370.

Hare, J.A. 2014. The future of fisheries oceanography lies in the pursuit of multiple hypotheses. ICES Journal of Marine Science 71 (8): 2343 2356. https://doi.org/10.1093/icesjms/fsu018.

Hidas, E.Z., K.G. Russell, D.J. Ayre, and T.E. Minchinton. 2013. Abundance of Tesseropora rosea at the margins of its biogeographic range is closely linked to recruitment, but not fecundity. Marine Ecology Progress Series 483: 199-208.

Hjort, J. 1914. Fluctuations in the great fisheries of northern Europe viewed in the light of biological research. Conseil Permanent International Pour l'Exploration de la Mer: Rapports et ProcèsVerbaux des Réunions 20: 228.

Honkoop, P.J.C., J. van der Meer, J.J. Beukema, and D. Kwast. (1998). Does temperature-influenced egg production predict the recruitment in the bivalve Macoma balthica? Marine Ecology Progress Series 164: 229-235.

Hughes, T.P., A.H. Baird, E.A. Dinsdale, N.A. Moltschaniwskyj, M.S. Pratchett, J.E. Tanner, and B.L. Willis. 2000. Supply-side ecology works both ways: the link between benthic adults, fecundity, and larval recruits. Ecology 81 (8): 2241-2249.

Hughes, T.P., J.T. Kerry, A.H. Baird, S.R. Connolly, T.J. Chase, A. Dietzel, T. Hill, A.S. Hoey, M.O. Hoogenboom, M. Jacobson, A. Kerswell, J.S. Madin, A. Mieog, A.S. Paley, M.S. Pratchett, G. Torda, and R.M. Woods. 2019. Global warming impairs stockrecruitment dynamics of corals. Nature 568 (7752): 387-390.

Hünerlage, K., V. Siegel, and R. Saborowski. 2019. Reproduction and recruitment of the brown shrimp in the inner German Bight (North Sea): an interannual study and critical reappraisal. Fisheries Oceanography 28 (6): 708-722.

Hurlbut, C.J. 1992. Larval release and supply predict temporal variation in settlement of a colonial ascidian. Marine Ecology Progress Series 80: $215-219$

Jackson, C.J., P.C. Rothlisberg, and R.C. Pendrey. 2001. Role of larval distribution and abundance in overall life-history dynamics: a study of the prawn. Penaeus semisulcatus in Albatross Bay, Gulf of Carpentaria, Australia. Marine Ecology Progress Series 213: 241252.

Johnson, D.W., M.R. Christie, T.J. Pusack, C.D. Stallings, and M.A. Hixon. 2018. Integrating larval connectivity with local demography reveals regional dynamics of a marine metapopulation. Ecology 99 (6): 1419-1429.

Kim, S.H., J.-H. Kim, S.R. Park, and K.-S. Lee. 2014. Annual and perennial life history strategies of Zostera marina populations under different light regimes. Marine Ecology Progress Series 509: 1-13.

Koster, F.W., D. Schnack, and C. Mollman. 2003. Scientific knowledge of biological process that are potentially useful in fish stock predictions. Scientia Marina 67 (Suppl. 1): 101-127.

Lee, T.N., C. Rooth, E. Williams, M.F. McGowan, A.F. Szmant, and M.E. Clarke. 1992. Influence of Florida current, gyres, and wind driven circulation transport of larvae and recruitment in the Florida Keys coral reefs. Continental Shelf Research 12 (7-8): 971-1002.

Lee, K.S., J.I. Park, Y.K. Kim, S.R. Park, and J.H. Kim. 2007. Recolonization of Zostera marina following destruction caused by a red tide algal bloom: the role of new shoot recruitment from seed banks. Marine Ecology Progress Series 342: 105-115. https://doi. org/10.3354/meps342105.

Levinton, J.S. 1995. Marine biology: function, biodiversity, ecology. Oxford University Press. (ISBN 0-19-508573-6, QH91.L427, Figure 5.24, p. 108).

Lipcius, R.N., and W.T. Stockhausen. 2002. Concurrent decline of the spawning stock, recruitment, larval abundance, and size of the blue 
crab Callinectes sapidus in Chesapeake Bay. Marine Ecology Progress Series 226: 45-61.

Marshall, D.J., and S.G. Morgan. 2011. Ecological and evolutionary consequences of linked life-history stages in the sea. Current Biology 21 (18): R718-R725.

McIlwain, J.L. 2002. Link between reproductive output and larval supply of a common damselfish species, with the evidence of replenishment from outside the local population. Marine Ecology Progress Series 236: 219-232.

McLeay, L., M. Doubell, I.S. Roberts, C. Dixon, L. Andreacchio, I.C. James, J. Luicki, and J. Middleton. 2016. A biophysical model to assess the trade-off between larval recruitment and catch in southern Australia's largest prawn fishery. Fisheries Oceanography 25 (2): 164-182.

McQuaid, C.D., and S.M. Lawrie. 2005. Supply-side ecology of the brown mussel, Perna perna: an investigation of spatial and temporal variation in, and coupling between, gamete release and larval supply. Marine Biology 147 (4): 955-963.

Meekan, M.G., M.J. Milicich, and P.J. Doherty. 1993. Larval production drives temporal patterns of larval supply and recruitment of a coral reef damselfish. Marine Ecology Progress Series 93: 217-225.

Morgan, G.R. 1989. Separating environmental and fisheries effects in the recruitment of Gulf shrimp. Kuwait Bulletin of Marine Science 10: $51-59$.

Morgan, S.G. 1995. Life and death in the plankton: larval mortality and adaptation. In Ecology of marine invertebrate larvae, ed. L. McEdward, 279-321. Florida: CRC.

Morgan, S.G. 2001. The larval ecology of marine communities. In Marine community ecology, ed. M. Bertness, S.D. Gaines, and M. Hay, 158-181. Massachusetts: Sinauer.

Morgan, G.R., B.F. Phillips, and L.M. Joll. 1982. Stock and recruitment relationships in Panulirus cygnus, the commercial rock (spiny) lobster of Western Australia. Fishery Bulletin 80: 475-486.

Morgan, S.G., J.L. Fisher, S.H. Miller, S.T. McAfee, and J.L. Largier. 2009. Nearshore larval retention in a region of strong upwelling and recruitment limitation. Ecology 90 (12): 3489-3502.

Morgan, S.G., A.L. Shanks, J.H. MacMahan, A.J.H.M. Reniers, C.D. Griesemer, Jarvis Marley, A. Fujimura, and J.A. Brown. 2017. Surf zones regulate larval supply and zooplankton subsidies to nearshore communities. Limnology and Oceanography 62 (6): 28112828.

Myers, R.A., and G. Mertz. 1998. Reducing uncertainty in the biological basis of fisheries management by meta-analysis of data from many populations: a synthesis. Fisheries Research 37 (1-3): 51-60. https://doi.org/10.1016/S0165-7836(98)00126-X.

Nozawa, Y., M. Tokeshi, and S. Nojima. 2006. Reproduction and recruitment of scleractinian corals in a high-latitude coral community, Amakusa, southwestern Japan. Marine Biology 149 (5): 1047-1058.

Ohlberger, J., L.A. Rogers, and N.C. Stenseth. 2014. Stochasticity and determinism: how density-independent and density-dependent processes affect population variability. PLoS One 9 (6): e98940. https:// doi.org/10.1371/journal.pone.008940.

Olesen, B. 1999. Reproduction in Danish eelgrass (Zostera marina L.) stands: size-dependence and biomass partitioning. Aquatic Botany 65 (1-4): 209-219. https://doi.org/10.1016/S0304-3770(99)000418.

Olive, P.J.W., P.R. Garwood, M.G. Bentley, and N. Wright. 1981. Reproductive success, relative abundance and population structure of two species of Nephtys in an estuarine beach. Marine Biology 63 (2): 189-196.

Olson, R.R. 1985. The consequences of short-distance larval dispersal in a sessile marine invertebrate. Ecology 66 (1): 30-39.

Olson, R.R., and R. McPherson. 1987. Potential vs realized larval dispersal: fish predation on larvae of the ascidian Lissoclinum patella (Gottschadt). Journal of Experimental Marine Biology and Ecology 110 (3): 245-256.
Paulik, G.J. 1973. Studies of the possible form of the stock-recruitment curve. Rapports et procès-verbaux des réunions Conseil International pour l'Exploration de la Mer 164: 302-315.

Penn, J.W., and N. Caputi. 1986. Spawning stock-recruitment relationships and environmental influences on the tiger prawn (Penaeus esculentus) fishery in Exmouth Gulf, Western Australia. Australian Journal of Marine and Freshwater Research 37 (4): 491-505.

Penn, J.W., N. Caputi, N., and N.G. Hall. 1995. Stock-recruitment relationships for the tiger prawn (Penaeus esculentus) stocks in Western Australia. ICES Marine Science Symposium 199: 320-333.

Pepin, P. 2016. Reconsidering the impossible — linking environmental drivers to growth, mortality, and recruitment of fish. Canadian Journal of Fisheries and Aquatic Sciences 73 (2): 205-215.

Peterken, C.J., and C.A. Conacher. 1997. Seed germination and recolonization of Zostera capricorni after grazing by dugongs. Aquatic Botany 59 (3-4): 333-340.

Petersen, J., and I.B. Svane. 1995. Larval dispersal in the ascidian Ciona intestinalis (L.). Evidence for a closed population. Journal of Experimental Marine Biology and Ecology 186 (1): 89-102.

Peterson, C.H., and H.C. Summerson. 1992. Basin-scale coherence of population dynamics of an exploited marine invertebrate, the bay scallop: implications of recruitment limitation. Marine Ecology Progress Series 90: 257-272.

Philippart, C.J.M., H.M. van Aken, J.J. Beukema, O.G. Bos, G.C. Cadée, and R. Dekker. 2003. Climate-related changes in recruitment of the bivalve Macoma baltica. Limnology and Oceanography 48: 21712185.

Pineda, J., N.B. Reyns, and V.R. Starczak. 2009. Complexity and simplification in understanding recruitment in benthic populations. Population Ecology 51 (1): 17-32.

Plus, M., J.M. Deslous-Paoli, and F. Dagault. 2003. Seagrass (Zostera marina L.) bed recolonization after anoxia-induced full mortality. Aquatic Botany 77 (2): 121-134.

Puckett, B.J., and D.B. Eggleston. 2016. Metapopulation dynamics guide marine reserve design: importance of connectivity, demographics, and stock enhancement. Ecosphere 7 (6): e01322. https://doi.org/10. 1002/ecs2.1322.

Raventos, N. 2009. Relationships between adult population size, recruitment, and year-class strength in a labrid fish in the Mediterranean Sea. Estuarine, Coastal and Shelf Science 85 (2): 167-172.

Reed, D.C., S.J. Holbrook, and C.A. Blanchette. 2009. Patterns and sources of variation in flowering, seed supply, and seedling recruitment in surfgrass Phyllospadix torreyi. Marine Ecology Progress Series 173: 13-23.

Robertson, D.R., D.G. Green, and B.C. Victor. 1988. Temporal coupling of production and recruitment of larvae of a Caribbean reef fish. Ecology 69 (2): 370-381.

Robertson, D.R., U.M. Schober, and J.D. Brawn. 1993. Comparative variation in spawning output and juvenile recruitment of some Caribbean reef fishes. Marine Ecology Progress Series 94: 105113.

Rognstad, R.L., D.S. Wethey, and T.J. Hilbish. 2014. Connectivity and population repatriation: limitations of climate and input into the larval pool. Marine Ecology Progress Series 495: 175-183.

Rollon, R.N., A.B. Rollon, M. Napo, B. Cayabyab, and M.D. Fortes. 2001. Vegetative dynamics and sexual reproduction of monospecific Thalassia hemprichii meadows in the Kalayaan Island Group. Aquatic Botany 71 (3): 239-246.

Rossetto, M., G.A. De Leo, A. Greenley, L. Vazquez, A. Saenz-Arroyo, J.A.E. Montes, and F. Micheli. 2013. Reproductive potential can predict recruitment rates in abalone. Journal of Shellfish Research 32 (1): 161-169.

Rothlisberg, P.C., P.D. Craig, and J.R. Andrewartha. 1996. Modelling penaeid prawn larval advection in albatross bay, Australia: defining 
the effective spawning population. Journal of Marine and Freshwater Research 47 (2): 157-168.

Ruiz-Montoya, L., R.J. Lowe, K.P. van Niel, and G.A. Kendrick. 2012. The role of hydrodynamics on seed dispersal in seagrasses. Limnology and Oceanography 57 (5): 1257-1265.

Rumrill, S.S. 1990. Natural mortality of marine invertebrate larvae. Ophelia 32 (1-2): 163-198.

Saenz-Agudelo, P., G.P. Jones, S.R. Thorrold, and S. Planes. 2011. Connectivity dominates larval replenishment in a coastal reef fish metapopulation. Proceedings of the Royal Society B 278 (2): 9542961.

Saenz-Agudelo, P., G.P. Jones, S.R. Thorrold, and S. Planes. 2015. Mothers matter: contribution to local replenishment is linked to female size, mate replacement and fecundity in a fish metapopulation. Marine Biology 162 (1): 3-14.

Sakuramoto, K. 2005. Does the Ricker or Beverton and Holt type of stock-recruitment relationship truly exist? Fisheries Science 71 (3): 577-592.

Satterthwaite, E.V. 2019. Positive stock-recruitment relationship persists in an intertidal metapopulation despite a mismatch between recruitment and habitat patch size. Davis, CA: Doctoral dissertation, University of California, Davis.

Shanks, A.L. 1995. Mechanisms of cross-shelf dispersal of larval invertebrates and fish. In Ecology of marine invertebrate larvae, ed. L. McEdward, 323-367. Florida: CRC.

Shelton, A.O. 2008. Skewed sex ratios, pollen limitation, and reproductive failure in the dioecious seagrass Phyllospadix. Ecology 89 (11): 3020-3029.

Smith, G.K., F. Guichard, F. Petrovi, and C.W. McKindsey. 2009. Spatial statistics to infer scales of demographic connectivity between populations of the blue mussel, Mytilus spp. Limnology and Oceanography 54 (3): 970-977.

Sponaugle, S., G. Boehlert, R. Cowen, C. Grimes, M. Kingsford, J. Leis, K. Lindeman, S. Morgan, J. Munro, J. Pineda, and A. Shanks. 2002. Predicting self-recruitment in marine populations: biophysical correlates. Bulletin of Marine Science 70: 341-376.

Stoner, D.S. 1990. Recruitment of a tropical colonial ascidian: relative importance of pre-settlement vs post-settlement processes. Ecology 71 (5): 1682-1690.

Stoner, D.S. 1992. Vertical distribution of a colonial ascidian on a coral reef: the roles of larval dispersal and life-history variation. The American Naturalist 139 (4): 802-824.

Strathmann, R.R., T.P. Hughes, A.M. Kuris, K.C. Lindeman, S.G. Morgan, J.M. Pandolfi, and R.R. Warner. 2002. Evolution of selfrecruitment and its consequences for marine populations. Bulletin of Marine Science 70: 377-396.

Strazisar, T., M.S. Kocha, T.A. Frankovich, and C.J. Madden. 2016. The importance of recurrent reproductive events for Ruppia maritima seed bank viability in a highly variable estuary. Aquatic Botany 134: 103-112.

Szuwalski, C.S., K.A. Vert-Pre, A.E. Punt, T.A. Branch, and R. Hilborn. 2015. Examining common assumptions about recruitment: a metaanalysis of recruitment dynamics for worldwide marine fisheries. Fish and Fisheries 16 (4): 633-648.

Thorrold, S.R., R.S. Burton, G.P. Jones, M.E. Hellberg, S.E. Swearer, J.E. Niegel, S.G. Morgan, and R.R. Warner. 2002. Quantifying larval retention and connectivity in marine populations with artificial and natural markers: can we do it right? Bulletin of Marine Science 70: $273-290$.

Thorson, G. 1950. Reproductive and larval ecology of marine bottom invertebrates. Biological Reviews 25 (1): 1-45.

Thresher, R.E. 1990. Reproduction in reef fishes. Vol. 399. Hong Kong: T.F.H. Publications.

Toupoint, N., L. Gilmore-Solomon, F. Bourque, B. Myrand, F. Pernet, F. Olivier, and R. Tremblay. 2012. Match/mismatch between the Mytilus edulis larval supply and seston quality: effect on recruitment. Ecology 93 (8): 1922-1934.

Travis, J., F.C. Coleman, P.J. Auster, P.M. Cury, J.A. Estes, J. Orensanz, C.H. Peterson, M.E. Power, R.S. Steneck, and J.T. Wootton. 2014. Integrating the invisible fabric of nature into fisheries management. Proceedings of the National Academy of Sciences of the United States of America 111 (2): 581-584. https://doi.org/10.1073/pnas. 1305853111.

Underwood, A.J., and M.J. Keough. 2001. Supply-side ecology: the nature and consequences of variations in recruitment of intertidal organisms. In Marine community ecology, ed. M. Bertness, S.D. Gaines, and M. Hay, 183-200. Massachusetts: Sinauer.

Urban, H.J. 2001. Reproductive strategies in tropical bivalves (Pteria colymbus, Pinctada imbricata and Pinna carnea): temporal coupling of gonad production and spat abundance related to environmental variability. Journal of Shellfish Research 20: 1127-1134.

Uriz, M.-J., M. Maldonado, X. Turon, and R. Marti. 1998. How do reproductive output, larval behaviour, and recruitment contribute to adult spatial patterns in Mediterranean encrusting sponges? Marine Ecology Progress Series 167: 137-148.

Van der Meer, J., J.J. Beukema, and R. Dekker. 2003. Large spatial variability in lifetime egg production in an intertidal Baltic tellin (Macoma balthica) population. Helgoland Marine Research 56 (4): $274-278$.

Wang, Y.G., and D. Die. 1996. Stock-recruitment relationships of the tiger prawns (Penaeus esculentus and Penaeus semisulcatus) in the Australian northern prawn fishery. Marine and Freshwater Research 47: 337-395.

White, J.W., S.G. Morgan, and J.L. Fisher. 2014. Larval mortality rates are lower than widely expected. Ecology 95 (12): 3344-3353.

Wing, S.R., M.T. Gibbs, and M.D. Lamare. 2003. Reproductive sources and sinks within a sea urchin, Evechinus chloroticus, population of a New Zealand fjord. Marine Ecology Progress Series 248: 109-123.

Xu, S., P. Wang, Y. Zhou, X. Zhang, R. Gu, X. Liu, B. Liu, X. Song, S. $\mathrm{Xu}$, and $\mathrm{S}$. Yue. 2018. New insights into different reproductive effort and sexual recruitment contribution between two geographic Zostera marina L. populations in temperate China. Frontiers in. Plant Science 9: 15. https://doi.org/10.3389/fpls.2018.00015.

Ye, C. 1984. The prawn (Penaeuus orientalis) in Pohai sea and their fishery. In Penaeid shrimps - their biology and management, pp. 49-60. ed. by J. A. Gulland, and B. J. Rothschild, 308. England: Fishing News Book Limited.

Ye, Y. 2000. Is recruitment related to spawning stock in penaeid shrimp fisheries. ICES Journal of Marine Science 57 (4): 1103-1109.

Yoshioka, P.M. 1982. Role of planktonic and benthic factors in the population dynamics of the bryozoan Membranipora membranacea. Ecology 63: 457468 .

Yoshioka, P.M. 1986. Chaos and recruitment in the bryozoan Membranipora membranace. Bulletin of Marine Science 39: 408417. 